\title{
Review: chemical approaches toward catalytic lignin degradation
}

\author{
Sara Gücyeter ${ }^{1} \cdot$ Richard Erpelding $^{2} \cdot$ Magnus S. Schmidt $^{1}$
}

Received: 30 July 2021 / Accepted: 23 November 2021 / Published online: 28 December 2021

(C) The Author(s) 2021

\begin{abstract}
Lignin is a potentially high natural source of biological aromatic substances. However, decomposition of the polymer has proven to be quite challenging, as the complex bonds are fairly difficult to break down chemically. This article is intended to provide an overview of various recent methods for the catalytic chemical depolymerization of the biopolymer lignin into chemical products. For this purpose, nickel-, zeolite- and palladium-supported catalysts were examined in detail. In order to achieve this, various experiments of the last years were collected, and the efficiency of the individual catalysts was examined. This included evaluating the reaction conditions under which the catalysts work most efficiently. The influence of co-catalysts and Lewis acidity was also investigated. The results show that it is possible to control the obtained product selectivity very well by the choice of the respective catalysts combined with the proper reaction conditions.
\end{abstract}

Keywords Lignin $\cdot$ Degradation $\cdot$ Catalytic depolymerization $\cdot$ Palladium $\cdot$ Zeolite $\cdot$ Nickel

\section{Introduction}

Lignin is a natural high source of aromatic chemicals. It can be found together with lignocellulose and cellulose in wooden plants and is the most common biopolymer in nature. Lignin is a heterogeneous alkyl-aromatic polymer that can comprise up to $30-40 \%$ of the plant cell wall by mass, depending on the plant type (Wang et al. 2013). Its primary functions in nature are for structure, water transport, and defense against pathogens. Lignin is found in trees and other lignocellulosic plant-based materials. Currently, lignin is mainly a by-product of the paper industry. However, the use of lignin in renewable energy and for the production of aromatic chemicals is very promising (Kleinert und Barth 2008; Ouyang et al. 2020; Pandey und Kim 2011). As the demands for renewable materials have significantly increased in the last decade, exploitation of biomass is gaining importance (Calvo-Flores und Dobado 2010; Guigo

Magnus S. Schmidt

magnus.schmidt@hs-furtwangen.de

1 Institute of Precision Medicine, Organic and Bioorganic Chemistry Lab, Medical and Life Sciences Faculty, Furtwangen University, Jakob-Kienzle-Str. 17, 78054 VS-Schwenningen, Germany

2 Institute of Applied Thermo- Und Fluiddynamics, University of Applied Sciences Konstanz, Alfred Wachtel-Straße 8, 78462 Konstanz, Germany et al. 2010). Lignin is typically used for gaining energy in combustion process (Windeisen und Wegener 2008; Kleinert und Barth 2008; Font et al. 2003). Merely, a small percentage is being used for regenerative purposes. Due to the complex structure of lignin (Scheme 1), it is extremely difficult and challengeable to break (Wang et al. 2013). Various approaches for the degradation of lignin have been investigated in the past decades from pyrolytic (Yang et al. 2007; Kawamoto 2017; Saiz-Jimenez und Leeuw 1986; Hosoya et al. 2007) up to biological methods with focuses on wood feeding insects (Geib et al. 2008) and fungi (Goodell 2003).

The catalytic chemical depolymerization of lignin is another promising method to generate small organic compounds, which can be used as basic chemicals in a wide range of industrial applications. Catalysts allow chemical conversions toward products with high stereo- and regioselectivity, as well as improved yields and positive effects on reaction conditions. In case of the depolymerization of lignin, where bonds are rather broken than formed, catalysts can have positive influence on product diversity and selectivity. Therefore, in this article, we would like to review the recent approaches of the past decade in this field of research with a focus on metal and zeolite catalysts including various cocatalytical combinations. 


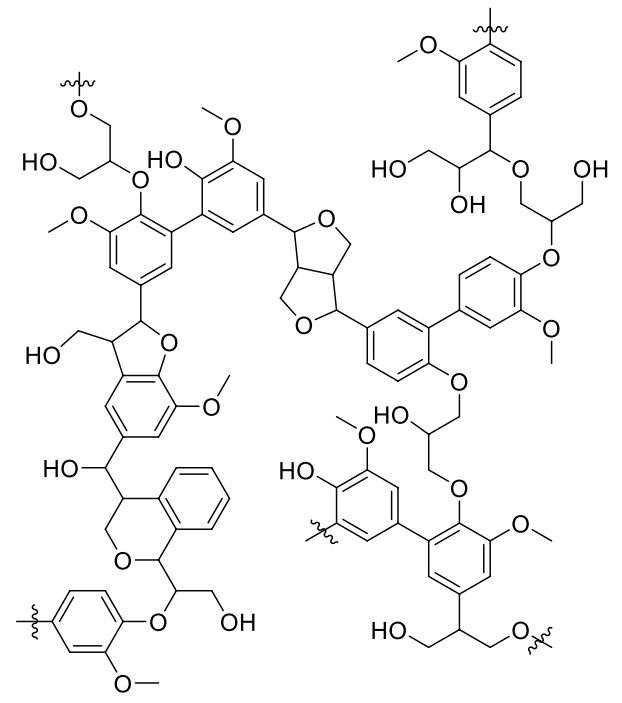

Scheme 1 Small section of the macromolecule with typical bonds and structures found in lignin

\section{Nickel catalyst}

\section{Metal catalyst: general heterogeneous catalytic reaction using $\mathrm{Ni} / \mathrm{C}$ catalyst}

A highly promising approach to achieve the depolymerization of lignin is through the use of heterogeneous metal catalysts. These are capable of degrading the $\mathrm{C}-\mathrm{O}$ and $\mathrm{C}-\mathrm{C}$ bonds of lignin (Luo et al. 2016). Consequently, a high lignin conversion is obtained. Furthermore, it has been shown that these reactions progress under moderate conditions (Luo et al. 2016). Studies and research provide that particularly nickel-based catalysts are highly effective as well as selective in the depolymerization of lignin into phenolic monomers (Song et al. 2013). Highly effective outcomes were obtained with supported nickel (Luo et al. 2016). In order to investigate the efficiency of nickel supported on activated carbon catalysts $(\mathrm{Ni} / \mathrm{C})$, several experiments were assembled and evaluated. These are briefly summarized in the following.
For the purpose of investigating the influence of Ni/C catalyst of the degradation of lignin, various experiments at different reaction conditions were conducted using Miscanthus, also called silvergrass (plants from the grass family, mainly cultivated as ornamental plants) as biomass (Luo et al. 2016). Table 1 illustrates the influence of different reaction conditions on a catalytic lignin depolymerization using different amounts of Ni/C catalysts. For this purpose, $1 \mathrm{~g}$ of milled Miscanthus was added to $45 \mathrm{~mL}$ of methanol $(\mathrm{MeOH})$. The mixtures were then heated for $12 \mathrm{~h}$ at $35 \mathrm{bar}$ $\mathrm{H}_{2}$ at $225^{\circ} \mathrm{C}$ (Luo et al. 2016). Under these reaction conditions, high yields were obtained particularly for the phenolic products $\mathbf{1 - 4}$. This is due to the Miscanthus, which is a grass species, so its lignocellulose contains mainly ferulate linkages (Luo et al. 2016). Therefore, the products $\mathbf{3}$ and $\mathbf{4}$ are characteristic products indicating these linkages. For this reason, higher yields are achieved by using Miscanthus than when conventional wood species are used (Luo et al. 2016). During the depolymerization of lignin in Miscanthus, a conversion yield to phenolic products of $68 \%$ can be observed. In the depolymerization of lignin obtained from wood species, only a conversion of $50 \%$ was achieved. This is due to the fact that the products 3 and $\mathbf{4}$ account for about $25 \%$ of lignin (Luo et al. 2016) (Scheme 2).

In the experiments, the effect of direct contact between the catalyst and the biomass on the reaction was investigated. Therefore, in the experiments $1-3$, the $\mathrm{Ni} / \mathrm{C}$ catalyst was separated from the biomass using a microporous cage (325 mesh, Luo et al. 2016). The experiments $4-6$ were carried out under the same conditions as experiments $1-3$. However,
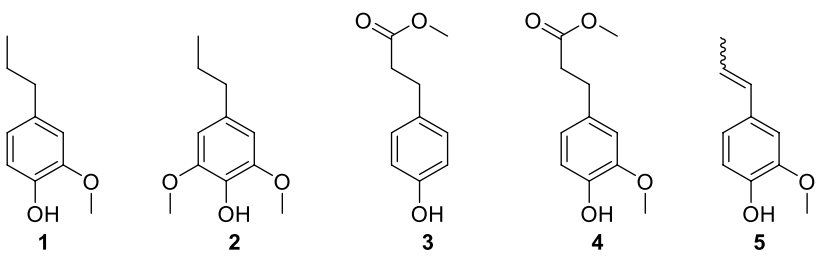

Scheme 2 Dihydroeugenol (1), Propylsyringol (2) Dihydro p-Coumaric acid methyl ester (3) Dihydro-ferulic acid methyl ester (4), Isoeugenol (5)
Table 1 Catalytic lignin depolymerization reaction with Miscanthus under different conditions (Luo et al. 2016)

\begin{tabular}{llllllll}
\hline Entry & \multicolumn{4}{c}{$\%$ yield of major phenolic products } & & Total \% yield & Conditions \\
\cline { 2 - 5 } & $\mathbf{1}$ & $\mathbf{2}$ & $\mathbf{3}$ & $\mathbf{4}$ & $\mathbf{5}$ & & \\
\hline 1 & 21 & 19 & 12 & 16 & & 68 & $15 \mathrm{wt} \% \mathrm{Ni} / \mathrm{C}$ in microporous cage \\
2 & 19 & 18 & 13 & 15 & & 65 & $10 \mathrm{wt} \% \mathrm{Ni} / \mathrm{C}$ in microporous cage \\
3 & 16 & 14 & 11 & 14 & 1 & 56 & $5 \mathrm{wt} \% \mathrm{Ni} / \mathrm{C}$ in microporous cage \\
4 & 22 & 20 & 10 & 15 & & 67 & $15 \mathrm{wt} \% \mathrm{Ni} / \mathrm{C}$ \\
5 & 19 & 18 & 12 & 16 & & 65 & $10 \mathrm{wt} \% \mathrm{Ni} / \mathrm{C}$ \\
6 & 11 & 12 & 8 & 13 & 9 & 53 & $5 \mathrm{wt} \% \mathrm{Ni} / \mathrm{C}$ \\
7 & - & & & & 22 & 22 & No catalyst \\
\hline
\end{tabular}


no microporous cage was used. The results show that quite similar results were obtained with both variants. This suggests that the lignin in the $\mathrm{MeOH}$ solution was depolymerized into oligomeric units and the soluble oligomeric fragments were then further converted to monomeric products by the $\mathrm{Ni} / \mathrm{C}$ catalyst (Luo et al. 2016). In general, the variation of the catalyst had only little effect on the achieved overall yields or on the distribution of the phenolic products apart from entry $6(5 \mathrm{wt} \% \mathrm{Ni} / \mathrm{C})$ which showed significant amounts of compound $\mathbf{5}$ with significant decreased amounts of compounds $\mathbf{1}$ and $\mathbf{2}$ and slightly decreased amounts of compounds 3 and 4 .

Other research also indicates that there is a dependence of the used biomass and the catalyst loading in terms of product scope and the monomer yields (Klein et al. 2015). This was demonstrated by a series of experiments in which three different feedstocks Birch, Poplar and Eucalyptus were added to 5 and $10 \mathrm{wt} \% \mathrm{Ni} / \mathrm{C}$ catalysts in $\mathrm{MeOH}$ (Klein et al. 2015). The results are summarized in Table 2 (Scheme 3).

1. Dihydroeugenol.

2. Propylsyringol.

5. Isoeugenol.

For this purpose, $4.0 \mathrm{~g}$ of ground of the feedstock (birch, poplar and eucalyptus) was put in an ethanol(EtOH)-benzene mixture (1:2) for $12 \mathrm{~h}$ in a Soxhlet extractor (Song et al. 2013). Subsequently, $2.0 \mathrm{~g}$ of the treated crushed birch wood was placed together with $0.10 \mathrm{~g}$ of the catalyst in $40 \mathrm{~mL}$ of $\mathrm{MeOH}$ in a $75-\mathrm{mL}$ autoclave reactor, which was then purged with Ar 4-6 times (Song et al. 2013). The reaction was then carried out at $200{ }^{\circ} \mathrm{C}$ for $6 \mathrm{~h}$ at a stirring speed of $500 \mathrm{rpm}$ (Klein et al. 2015). For every substrate, experiments with $5 \mathrm{wt} \% \mathrm{Ni} / \mathrm{C}$ and with $10 \mathrm{wt} \% \mathrm{Ni} / \mathrm{C}$ were carried out. The results of the first three experiments show that birch wood seems to be more suitable for the depolymerization of lignin than the other used feedstocks, as it exhibits the highest lignin yield of $20 \%$. This could possibly be attributed to the fact that birch wood contains a lower amount of xylan and that birch wood displays a higher uniformity of lignin referred to the various possible bonds in lignin, allowing a more selective catalytic depolymerization (Klein et al. 2015). The primary products of both birch and eucalyptus
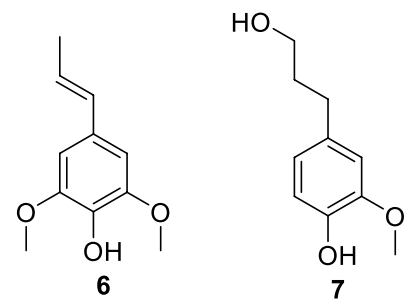

Scheme 3 Mi-EuOH (6), 4-(3-Hydroxypropyl)-2-methoxyphenol (7)

were compounds 5 and $\mathbf{6}$, with $8 \%$ and $12 \%$ for birch and $6 \%$ and $8 \%$ for eucalyptus, respectively. Experiments 4 to 6 , using $10 \mathrm{wt} \% \mathrm{NiC}$ catalyst loading, show a significant difference in the yields and in the products obtained. The product yields increased significantly for all three substrates. In particular, for the poplar and eucalyptus substrates, the yields progressed from 6 and $16 \%$ to $26 \%$ and $28 \%$, respectively. The data suggest that in the presence of $10 \mathrm{wt} \% \mathrm{Ni} / \mathrm{C}$, hydrogenation of the obtained products $\mathbf{5}$ and $\mathbf{6}$ result in the formation of the products $\mathbf{2}$ and $\mathbf{7}$ (Klein et al. 2015). Furthermore, a considerable increase in pressure was observed in experiments 4 to 6 . This may be caused by the higher formation of $\mathrm{H}_{2}$ by the use of $\mathrm{MeOH}$ in the presence of 10 wt $\% \mathrm{Ni} / \mathrm{C}$ (Klein et al. 2015).

1. Dihydroeugenol.

2. Propylsyringol.

8. Alkene-substituted dihydroeugenol and propylsyringol.

9. Dimers.

Table 3 summarizes experiments conducted to examine the activity of $\mathrm{Ni} / \mathrm{C}$ catalysts in the depolymerization of lignin using different kinds of solvents. For this purpose, $2.0 \mathrm{~g}$ of the pretreated birch sawdust and $0.10 \mathrm{~g}$ of the $\mathrm{Ni} / \mathrm{C}$ catalyst were mixed with $40 \mathrm{~mL}$ of the used solvent at $200{ }^{\circ} \mathrm{C}$ and a stirring speed of $500 \mathrm{rpm}$ for $6 \mathrm{~h}$ in an autoclave reactor. The reactor was then cooled to room temperature (Song et al. 2013). The first entry of the conducted experiments shows that without the use of the catalyst lignin cannot be depolymerized to phenolic products, as the various linkages cannot be cleaved. By using $\mathrm{MeOH}$ as a solvent a lignin conversion of $54 \%$ was
Table 2 Depolymerization results of birch, poplar and eucalyptus wood with 5 and 10 $\mathrm{wt} \% \mathrm{Ni} / \mathrm{C}$ catalysts in $\mathrm{MeOH}$ (Klein et al. 2015)

\begin{tabular}{llllllllll}
\hline Entry & Substrate & $\begin{array}{l}\text { Ni/C catalyst } \\
\text { loading }\end{array}$ & $\mathbf{1}$ & $\mathbf{5}$ & $\mathbf{2}$ & $\mathbf{6}$ & $\mathbf{7}$ & Total \% yield & $\begin{array}{l}\text { Final pres- } \\
\text { sure (bar) }\end{array}$ \\
\hline 1 & Birch & $5 \mathrm{wt} \%$ & - & 8 & - & 12 & - & 20 & 3.5 \\
2 & Poplar & $5 \mathrm{wt} \%$ & - & 2 & - & 2 & 2 & 6 & 2.4 \\
3 & Eucalyptus & $5 \mathrm{wt} \%$ & - & 6 & - & 8 & 2 & 16 & 3.6 \\
4 & Birch & $10 \mathrm{wt} \%$ & 10 & 1 & 18 & 3 & - & 32 & 9.4 \\
5 & Poplar, & $10 \mathrm{wt} \%$ & 1 & 8 & 2 & 15 & - & 26 & 5.5 \\
6 & Eucalyptus & $10 \mathrm{wt} \%$ & 6 & 3 & 8 & 11 & - & 28 & 8.5 \\
\hline
\end{tabular}


Table 3 Results using different solvents for catalytic lignin depolymerization (Song et al. 2013)

\begin{tabular}{|c|c|c|c|c|c|c|c|}
\hline \multirow[t]{2}{*}{ Entry } & \multirow[t]{2}{*}{ Catalyst } & \multirow[t]{2}{*}{ Solvent } & \multirow[t]{2}{*}{ Yield. (\%) } & \multicolumn{4}{|c|}{ Products } \\
\hline & & & & 1 & 2 & 8 & 9 \\
\hline 1 & No catalyst & $\mathrm{MeOH}$ & Not detected & - & - & - & - \\
\hline 2 & $\mathrm{Ni} / \mathrm{C}$ & $\mathrm{MeOH}$ & 54 & 22 & 67 & 1 & 10 \\
\hline 3 & $\mathrm{Ni} / \mathrm{C}$ & $\mathrm{EtOH}$ & 48 & 25 & 70 & 3 & 2 \\
\hline 4 & $\mathrm{Ni} / \mathrm{C}$ & Ethylene glycol & 50 & 25 & 72 & 1 & 2 \\
\hline 5 & $\mathrm{Ni} / \mathrm{C}$ & iPrOH & 27 & 12 & 37 & 26 & 25 \\
\hline 6 & $\mathrm{Ni} / \mathrm{C}$ & $25 \%$ glycerol $+\mathrm{H} 2 \mathrm{O}$ & 16 & 16 & 67 & - & 17 \\
\hline 7 & $\mathrm{Ni} / \mathrm{C}$ & 1,4-Dioxane & 15 & - & 6 & 93 & $<1$ \\
\hline 8 & $\mathrm{Ni} / \mathrm{C}$ & $1 \% \mathrm{MeOH}+\mathrm{H} 2 \mathrm{O}$ & 9 & 31 & 63 & - & 6 \\
\hline 9 & $\mathrm{Ni} / \mathrm{C}$ & $25 \% \mathrm{MeOH}+\mathrm{H} 2 \mathrm{O}$ & 22 & 16 & 74 & - & 11 \\
\hline 10 & $\mathrm{Ni} / \mathrm{C}$ & Cyclohexane & $<1$ & - & - & - & - \\
\hline
\end{tabular}

obtained (Song et al. 2013). Furthermore, a total selectivity of products 8 and $\mathbf{9}$ of $89 \%$ can be achieved. Next, EtOH and ethylene glycol (EG) were used as solvents. The experimental data of entries 3 and 4 show extremely similar results both in lignin conservation, which is about $50 \%$, and in the selectivity of the products. In the fifth entry, isopropanol (iPrOH) was used, and the experimental results show that it is less efficient than $\mathrm{MeOH}$. It has a very low lignin dissolution capacity, resulting in a lignin yield of merely $27 \%$ (Song et al. 2013). An equally inefficient lignin yield of $16 \%$ was achieved when using glycerol aqueous solution (25 vol\%). This is due to the high viscosity (Song et al. 2013). 1,4-dioxane has the property of dissolving lignin. 1,4-dioxane differs fundamentally from alcohols. For example, it lacks hydrogenation capabilities. This was evident in the fact that propenyl-substituted phenols were formed (Song et al. 2013). In entries 8 and 9 , mixtures of $\mathrm{MeOH}$ and water were used as solvents. Both experiments demonstrate that the use of pure $\mathrm{MeOH}$ provides much better results. With both mixtures, only low lignin yields of $9 \%$ and $22 \%$ were obtained. The product selectivity was also affected and much lower. The experiments show that a higher $\mathrm{MeOH}$ content in the solutions results in a higher lignin yield (Song et al. 2013). In the tenth entry, cyclohexane was used, in which no lignin yield was obtained. This is due to the fact that possibly no hydrogen can be formed under the reaction conditions and that lignin has a very poor dissolubility (Song et al. 2013). It was observed that especially alcoholic solvents performed well. This can be attributed to the fact that the polar groups contained in the lignin interact with the alcohol molecules of the solvent, which promotes the depolymerization of lignin (Shu et al. 2015). Alcohols such as $\mathrm{MeOH}, \mathrm{EtOH}$, propanol and butanol are particularly suitable for this purpose because they exhibit a strong Lewis base (Shu et al. 2015). In addition, products such as monomers can dissolve excellently in alcohols. This also prevents repolymerization. The following equations were used to determine the yields (Song et al. 2013).

$\frac{\text { The weight of total detected products }}{\text { the weight of lignin added as birch sawdust }} \times 100=$ yield [\%]

The intergrated GC area of products

The total intergrated area of all detected products

$\times 100=$ selectivity $[\%]$

It can be concluded that several different factors influence the efficiency of a heterogeneous catalytic reaction using nickel supported on activated carbon catalysts. The usage of a microporous cage, in order to separate the catalyst and the biomass, showed only very little effects, whereas the use of the substrate is very important. Birch wood was shown to be more efficient in the depolymerization of lignin than the usage other feedstocks like eucalyptus. In addition, the choice of solvent is very crucial. A number of experiments have shown that $\mathrm{MeOH}$ is particularly suitable for this purpose (Table 4).

\section{Heterogeneous catalyst RANEY Nickel}

The use of RANEY nickel as a catalyst has been shown to support the production of phenols (Forchheim et al. 2012). Besides achieving a high phenol yield, another benefit of using Raney nickel is that they are very low cost (Zhao et al. 2010). Raney nickel is capable of serving as a catalyst in the hydrogenolysis of ether bonds (Wang und Rinaldi 2012). In order to demonstrate the influence of the heterogeneous catalyst RANEY nickel on the degradation of lignin various experiments were conducted and are presented in the following. For this purpose, experiments investigating the process of hydrogenolysis were performed. Thereby, the effect of the used solvent and the resulting products were analyzed. 
Table 4 Products of the hydrogenolysis of diphenyl ether conducted in different solvents (Wang und Rinaldi 2012)

\begin{tabular}{llllllllllll}
\hline Entry & Solvent & Yield \% & \multicolumn{9}{l}{ Selectivity } \\
\cline { 3 - 11 } & & & $\mathbf{1 0}$ & $\mathbf{1 1}$ & $\mathbf{1 2}$ & $\mathbf{1 3}$ & $\mathbf{1 4}$ & $\mathbf{1 5}$ & $\mathbf{1 2 :} \mathbf{1 4}$ & $\mathbf{1 3 :} \mathbf{1 5}$ & $\mathbf{S}(\mathbf{1 2 , 1 4}) / \mathbf{S}(\mathbf{1 3 , 1 5})$ \\
\hline 1 & MeOH & 12.4 & 13.7 & 0 & 25.7 & 32.3 & 16.8 & 11.5 & 1.53 & 2.81 & 0.97 \\
2 & EtOH & 33.0 & 11.8 & 0.3 & 10.7 & 26.7 & 33.6 & 16.9 & 0.32 & 1.58 & 1.02 \\
3 & iPrOH & 72.2 & 15.0 & 1.9 & 1.6 & 15.4 & 40.5 & 25.6 & 0.04 & 0.60 & 1.03 \\
4 & Hex-F-2-PrOH & 100.0 & 0.0 & 67.3 & 0 & 0 & 16.6 & 16.1 & 0 & 0 & 1.03 \\
5 & 1-Butanol & 32.0 & 9.3 & 0.7 & 9.2 & 22.5 & 36.8 & 21.5 & 0.25 & 1.05 & 1.05 \\
6 & 2-Butanol & 55.1 & 15.4 & 0.8 & 10.3 & 18.0 & 32.1 & 23.4 & 0.32 & 0.77 & 1.02 \\
7 & t-Butanol & 21.7 & 20.4 & 1.4 & 18.4 & 17.2 & 21.4 & 21.2 & 0.86 & 0.81 & 1.04 \\
8 & Ethyl acetate & 47.0 & 21.0 & 1.8 & 8.1 & 15.7 & 30.1 & 23.3 & 0.27 & 0.67 & 0.98 \\
9 & tetrahydrofuran & 29.6 & 15.5 & 0 & 14.2 & 25.3 & 27.6 & 17.4 & 0.51 & 1.45 & 0.98 \\
10 & 2-Me-THF & 61.1 & 24.1 & 1.7 & 2.9 & 12.8 & 34.4 & 24.1 & 0.08 & 0.53 & 1.01 \\
11 & 1,4-dioxane & 17.8 & 24.5 & 0 & 24.1 & 22.0 & 13.3 & 16.1 & 1.81 & 1.37 & 0.98 \\
12 & n-heptane & 99.0 & 9.6 & 36.5 & 0 & 1.5 & 27.5 & 24.9 & 0 & 0.06 & 1.04 \\
13 & Decaline & 99.6 & 6.3 & 41.4 & 0 & 0 & 26.6 & 25.7 & 0 & 0 & 1.04 \\
14 & MCH & 100 & 0 & 55.4 & 0 & 0 & 22.8 & 21.8 & 0 & 0 & 1.05 \\
\hline
\end{tabular}

Furthermore, the obtained product selectivity was observed by executing hydrothermal lignin degradation experiments.

\section{Hydrogenolysis of diphenyl ether with Raney $\mathrm{Ni}$ conducted in several solvents}

10. Cyclohexyl phenyl ether.

11. Dicyclohexyl ether.

12. Phenol.

13. Benzene.

14. Cyclohexanol.

15. Cyclohexane.

For the hydrogenolysis of diphenyl ether, $100 \mathrm{mg}$ of RANEY nickel, $2.9 \mathrm{mmol}$ of diphenyl ether and $15 \mathrm{~mL}$ of the used solvent were added in a 30-mL batch reactor, which was then purged with hydrogen (Wang und Rinaldi 2012). Afterward, the reactor was heated from an initial pressure of $50 \mathrm{bar} \mathrm{H}_{2}$ at $25^{\circ} \mathrm{C}$ to $90{ }^{\circ} \mathrm{C}$ for $10 \mathrm{~min}$. The reaction took $2.5 \mathrm{~h}$ and was conducted at a stirring rate of $300 \mathrm{rpm}$. Afterward, the obtained products were analyzed by using GC-FID and GC-MS (Wang und Rinaldi 2012).

The experiment has shown that the reaction is significantly influenced by the used solvent. Using alcohols as solvents, $\mathrm{iPrOH}$ in particular was found to be effective, with a conversion of $72.7 \%$, followed by 2-butanol, which yielded a conversion of $55.1 \%$. Worse results were achieved by using EtOH, 1-butanol and tert-butanol. The worst outcome was obtained using $\mathrm{MeOH}$, with a conversion of only $12.4 \%$ (Wang und Rinaldi 2012). Moderate results were obtained using 2-Me-THF with a conversion of $61.1 \%$ and ethyl acetate with a conversion of $47.0 \%$. In contrast, the use of tetrahydrofuran and 1,4-dioxane achieved poor results with conversions of $29.6 \%$ and $17.8 \%$, respectively (Wang und
Rinaldi 2012). By using alkanes as solvents, excellent results were achieved. This was evident from the fact that when $\mathrm{n}$-heptane and decalin were used, almost complete conversions of $99.0 \%$ and $99.6 \%$, respectively, were achieved. By using methylcyclohexane (MCH), a conversion of $100 \%$ was realized. An equally great outcome was observed by using 1,1,1,3,3,3-Hexafluoro-2-propanol (Hex-F-2-PrOH), in which the substrate was likewise completely converted (Wang und Rinaldi 2012). The use of RANEY nickel is favorable as it allows the hydrogenolysis of ethers and the hydrogenation of arenes (Wang und Rinaldi 2012). The experiments on phenol/cyclohexanol and benzene/cyclohexane ratios indicate that the type of solvent can enhance selectivity (Wang und Rinaldi 2012). The highest aromatic yield was achieved by using $\mathrm{MeOH}$ and 1,4-dioxane. This was reflected in the high yields of phenol and benzene. The use of alkanes and hex-F-2-PrOH, on the other hand, provided extremely poor results with almost no resulting aromatic yields. The results suggest that the formation of aromatics occurs only by hydrogenolysis of the ether bond. RANEY nickel is suitable for catalyzing the hydrogenation of phenol to cyclohexanol, but for the conversion of phenols to alkanes, an additional acid catalyst is required (Wang und Rinaldi 2012) (Scheme 4).

\section{Spruce lignin hydrogenolysis}

The gas-liquid chromatography of spruce lignin hydrogenolysis products in which Raney nickel, ruthenium on charcoal and ruthenium on alumina was used as catalysts revealed the formation of nine compounds. Among them, four compounds were identified as aromatic derivatives and five as cyclohexyl derivatives (Pepper and Lee, 1970). A 
Scheme 4 4-methylguaiacol (18), 4-ethylguaiacol (20)

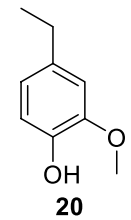

20

pure sample was taken from the gas chromatograph for each compound. They were then compared to an accurate sample for their relative retention time and their mass. Infrared (i.r.), and nuclear magnetic resonance (n.m.r.) spectra (J. M. Pepper and Y. W. Lee). The relative abundance of the lignin degradation products obtained was determined for all three catalysts used. For this purpose, dihydrosinapyl alcohol was used as an internal standard (J. M. Pepper and Y. $\mathrm{W}$. Lee). The abundances were then reported in terms of the weight percentage of the total ether-soluble fraction (J. M. Pepper and Y. W. Lee). Both a planimeter and the triangulation method were used for the determination. The average of the values obtained was then used (J. M. Pepper and Y. W. Lee). In the following experiment, lignin degradation was achieved by a hydrogenolysis process. For this purpose, $10 \mathrm{~g}$ of extracted spruce wood flour was heated in dioxine water $(1: 1 \mathrm{v} / \mathrm{v}, 150 \mathrm{~mL})$ at a temperature of $195^{\circ} \mathrm{C}$ and at an starting hydrogen pressure of $34.5 \mathrm{bar}$ for $5 \mathrm{~h}$ (J. M. Pepper and Y. W. Lee). This process was repeated using the individual catalysts. In the first experiment, $10 \mathrm{~g}$ of Raney nickel was used (J. M. Pepper and Y. W. Lee). An F\&M chromatograph of the model 5750 was used for the study. The dimensions of the column were 1/8 inch, 6 feet and it was filled with $10 \%$ SE-30 Chromosorb W. In addition, the helium flow rate was $40 \mathrm{~mL} / \mathrm{min}$ (J. M. Pepper and Y. W. Lee). The temperature was heated from 100 to $250{ }^{\circ} \mathrm{C}$ at a rate of $4 \% \mathrm{~min}$. The results of the study are provided in Table 5. They show that the use of the catalysts leads to an increased lignin degradation. In addition, a ring reduction to the corresponding cyclohexyl derivatives could be observed (J. M. Pepper and Y. W. Lee). The main components obtained were those containing a 1-substituted-3-propanol structure (J. M. Pepper and Y. W. Lee). Compared to the ruthenium catalysts supported on char coal or alumina, the use of Raney nickel as a catalyst achieved the highest lignin yield of $16.5 \%$ (J. M. Pepper and Y. W. Lee). The use of Raney nickel particularly favored the recovery of the 3-(4-hydroxycyclohexyl)-1-propanol component. (J. M. Pepper and Y. W. Lee) (Scheme 5).

\section{Hydrothermal lignin degradation experiments}

\section{Phenol.}

18. 4-methylguaiacol.

25. 4-Methyl-catechol.

26. Methane.

27. $\mathrm{C}_{2}-\mathrm{C}_{4}$

28. Carbon dioxide.

For the hydrolysis of lignin, $3 \mathrm{~mL}$ of water, $0.4 \mathrm{~g}$ of lignin (spruce) and $0.1 \mathrm{~g}$ of RANEY nickel were added to a $5-\mathrm{mL}$ microbatch reactor and heated at varying temperatures and time periods for different experiments (Forchheim et al. 2012). The used spruce wood was prior subjected to the simultaneous saccharification and fermentation process. The gaseous and organic phases were analyzed using gas chromatography (Forchheim et al. 2012). The experiment demonstrated that RANEY nickel as a catalyst affects the selectivity of phenol (12). This effect can be seen in particular in the experiments carried out at a temperature of $633 \mathrm{~K}$ (entries 5-7) (Forchheim et al. 2012). Here, a relatively high phenol (12) yield was obtained, whereas the yield of guaiacol (23) and catechol (24) remained rather low. The formation of phenol (12) as well as p-cresol (22) could be strongly supported by increasing the temperature as well as the reaction time. However, these changes led to a decrease in the formation of the products guaiacol and catechol (Forchheim et al. 2012). In addition, the impact of the reaction conditions on the yield of the solid residue could be evaluated. In general, increasing the temperature and reaction time resulted in a decrease in yield. In the experiments that lasted $1200 \mathrm{~min}$ (entries 4 and 10), the yield equaled $0 \%$ (Forchheim et al. 2012). The study has shown that Raney nickel promotes gasification under certain reaction conditions (Forchheim et al. 2012). In particular, the experiments with an increased temperature showed a high gas formation. Carbon dioxide was formed most frequently,

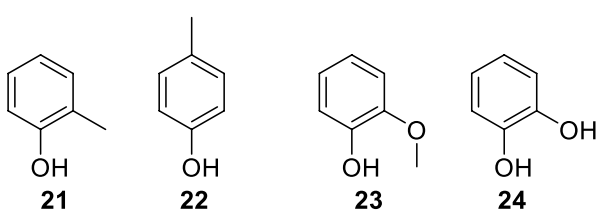

Scheme 5 o-Cresol (21), p-Cresol (22), Guaiacol (23), Catechol (24)
Table 5 Gas-liquid chromatographic analysis of ether-soluble spruce lignin hydrogenolysis products (J. M. Pepper and Y. W. Lee)

\begin{tabular}{|c|c|c|c|c|c|c|c|c|c|c|c|c|}
\hline \multirow[t]{2}{*}{ Entry } & \multirow[t]{2}{*}{ Catalyst } & \multicolumn{9}{|c|}{ Selectivity } & \multirow[t]{2}{*}{ Total } & \multirow[t]{2}{*}{ Yield } \\
\hline & & 16 & 17 & $\mathrm{C}$ & 18 & $\mathrm{D}$ & $\mathrm{E}$ & 19 & 20 & $\mathrm{~F}$ & & \\
\hline 1 & RANEY-Nickel & 0.66 & 0.83 & 1.00 & 1.69 & 1.00 & 0.87 & 40.9 & 12.6 & 6.32 & 65.9 & 16.5 \\
\hline 2 & $\mathrm{Ru}-\mathrm{C}$ & 1.56 & 3.49 & 1.39 & 0.32 & 2.70 & 1.61 & 6.95 & 4.52 & 10.3 & 32.8 & 11.8 \\
\hline 3 & $\mathrm{Ru}-\mathrm{Al}$ & 0.67 & 1.72 & 0.97 & 1.05 & 2.02 & 2.51 & 19.8 & 12.2 & 15.2 & 56.1 & 14.6 \\
\hline
\end{tabular}


followed by the formation of methane. In addition, a small amount of hydrocarbon gases was produced. It could be observed that the formation of all mentioned gases was favored by an increase in the reaction temperature and time (Forchheim et al. 2012). Furthermore, it was observed that by the presence of RANEY nickel catechol was converted to phenol (12). Cyclohexanol (14), on the other hand, was not formed. This could possibly be due to the fact that the temperature is unsuitable for this purpose and that an insufficient amount of hydrogen is present (Forchheim et al. 2012). The formation of phenol was the result of liquefaction. The experiment has shown that RANEY nickel is not able to induce the formation of monoaromatic compounds. However, the use of RANEY nickel as a catalyst leads to the hydrogenation of intermediate products of lignin degradation such as guaiacol and catechol from which phenol can be obtained (Forchheim et al. 2012). Since high temperatures and long reaction times increase the formation of phenols, it is expected that a high phenol yield requires a considerable amount of time. Since the increase in temperature and time also results in gasification, it is likely that the phenol yield will eventually decrease over extended reaction times (Forchheim et al. 2012) (Tables 6 and 7).

By increasing the temperature of the reaction, the obtained product selectivity can be diversified. Furthermore using RANEY nickel, the gasification of guaiacol and catechol is favored by a higher reaction temperature, which results in the generation of aromatic products. However, very high temperatures promote the gasification of guaiacol. The formation of gas results in a lower aromatic yield. The formation of solid residue is suppressed near critical water, as RANEY nickel suppresses the formation of intermediates that can lead to polymerize (Forchheim et al. 2012). It can be concluded that solvents are able to direct the product selectivity. Therefore, it must be considered wisely which solvent is best suited for conversion of lignin by hydrogenolysis of C-O ether bonds (Wang und Rinaldi 2012).

\section{Nickel Zeolite}

In all three experiments, a $300-\mathrm{mL}$ batch reactor was used. $0.5 \mathrm{~g}$ of $\mathrm{Ni}$ catalyst and $1 \mathrm{~g}$ of organosolv lignin and $100 \mathrm{ml}$ (77 g) of hexadecane solvent were added to the reactor. $1 \mathrm{ml}$ of $\mathrm{n}$-heptane was used as an internal standard. The reactor was then purged 3 times with hydrogen. Afterward, it was heated at a pressure of $20 \mathrm{bar} \mathrm{H}_{2}$ to $523 \mathrm{~K}$ or $593 \mathrm{~K}$ within 15 min (Kasakov et al. 2015). The used stirring rate was $700 \mathrm{rpm}$. Finally, the reaction was terminated by cooling to room temperature. Different acidic zeolites have been used such as HZSM-5, which has a monoclinic framework (Vankoningsveld et al. 1990) and HBEA. To prepare the catalysts for the reaction, $2 \mathrm{~g}$ of zeolite and $210 \mathrm{~mL}$ of a
Table 6 Results of hydrothermal lignin degradation experiments (Forchheim et al. 2012)

\begin{tabular}{|c|c|c|c|c|c|c|c|c|c|c|c|c|c|}
\hline \multirow[t]{2}{*}{ Entry } & \multirow[t]{2}{*}{ Time [Min] } & \multirow{2}{*}{$\begin{array}{l}\text { Tem- } \\
\text { perature } \\
{[\mathrm{K}]}\end{array}$} & \multirow[t]{2}{*}{ Solid residue } & \multicolumn{10}{|c|}{ Selectivity } \\
\hline & & & & 12 & 21 & 22 & 23 & 18 & 24 & 25 & 26 & 27 & 28 \\
\hline 1 & 30 & 573 & 361.3 & 0.6 & 0.0 & 0.0 & 1.5 & 0.4 & 1.2 & 0.0 & 15.3 & 3.1 & 245.7 \\
\hline 2 & 30 & 603 & 268.4 & 2.1 & 0.2 & 0.6 & 4.0 & 1.0 & 1.7 & 1.0 & 32.4 & 7.6 & 322.8 \\
\hline 3 & 270 & 603 & 98.1 & 9.1 & 0.6 & 2.8 & 2.2 & 0.8 & 3.4 & 1.8 & 31.7 & 7.3 & 584.4 \\
\hline 4 & 1200 & 603 & 1.7 & 12.5 & 0.8 & 7.5 & 0.0 & 0.3 & - & 0.0 & 34.3 & 11.5 & 533.4 \\
\hline 5 & 30 & 633 & 193.3 & 3.8 & 0.3 & 1.3 & 4.0 & 2.0 & 1.6 & 1.2 & 39.8 & 9.0 & 510.9 \\
\hline 6 & 120 & 633 & 131.9 & 8.8 & 0.7 & 4.4 & 1.1 & 2.6 & 0.5 & 1.6 & 48.6 & 9.4 & 389.7 \\
\hline 7 & 270 & 633 & 90.6 & 9.6 & 0.7 & 6.2 & 0.1 & 0.9 & - & 0.3 & 40.1 & 9.1 & 751.2 \\
\hline 8 & 30 & 673 & 101.7 & 6.7 & 0.6 & 3.4 & 2.3 & 1.0 & 7.0 & 3.9 & 41.0 & 8.1 & 684.7 \\
\hline 9 & 270 & 673 & 34.0 & 12.2 & 1.1 & 8.6 & 0.0 & 0.5 & 0.4 & 0.3 & 46.1 & 15.8 & 212.5 \\
\hline 10 & 1200 & 673 & 0.0 & 8.5 & 0.4 & 10.6 & 0.0 & 0.8 & - & 0.0 & 67.9 & 19.7 & 773.1 \\
\hline
\end{tabular}

Table 7 Yield and selectivity of liquid and gas phase hydrocarbons for beech lignin conversion catalyzed by $\mathrm{Ni}$ catalysts in n-hexadecane (Kasakov et al. 2015)

\begin{tabular}{llllll}
\hline Catalysts & $\begin{array}{l}\text { Gas phase } \\
\text { Products [wt\%] } \\
\left(\mathrm{CH}_{4}, \mathrm{C}_{3} \mathrm{H}_{8},\right.\end{array}$ & $\begin{array}{l}\text { Liquid phase } \\
\text { products [wt\%] }\end{array}$ & & \multicolumn{2}{l}{ Selectivity within liquid mix [wt\%] } \\
\cline { 5 - 6 } & $\left.\mathrm{CH}_{4} \mathrm{O}\right)$ & $\begin{array}{l}\text { Monocyclic } \\
\text { alcohols }\end{array}$ & $\begin{array}{l}\text { Monocyclic } \\
\text { Alkanes } \\
\left(\mathrm{C}_{5}-\mathrm{C}_{9}\right)\end{array}$ & $\begin{array}{l}\text { Bicyclic } \\
\text { Alkanes } \\
\left(>\mathrm{C}_{9}\right)\end{array}$ \\
\hline $\mathrm{Ni} / \mathrm{SiO}_{2}$ & 4.1 & $23 \pm 2$ & 20 & 80 & 0 \\
$\mathrm{Ni} / \mathrm{HZSM}-5$ & 5.5 & $28 \pm 2$ & 0 & 90 & 10 \\
$\mathrm{Ni} / \mathrm{HBEA}$ & 6.8 & $35 \pm 4$ & 0 & 83 & 17 \\
\hline
\end{tabular}


$0.14 \mathrm{M} \mathrm{Ni}\left(\mathrm{NO}_{3}\right)_{2}$ solution were used. Also, $10.2 \mathrm{~g}$ of urea was dissolved in $40 \mathrm{~mL}$ of the $\mathrm{Ni}(\mathrm{NO} 3) 2$ solution. The urea nickel solution was added to the nickel zeolite solution at a temperature of $343 \mathrm{~K}$. Subsequently, the temperature was heated to $363 \mathrm{~K}$ at and then after $3 \mathrm{~h}$ cooled to the ambient temperature. The solution was added to the nickel zeolite solution. The suspension was additionally vacuum-filtered. The resulting solid was rinsed 3 times with ultrapure water and incubated overnight at $383 \mathrm{~K}$. The same procedure was performed to prepare the silica catalyst; however, the suspension was cooled after $3.5 \mathrm{~h}$. The resulting gas was analyzed using Agilent Technologies 7890B GC and thermal conductivity and flame ionization detectors (TCD and FID). The collected liquid phase was also analyzed using an Agilent Technologies 7890B GC. The yield was determined using the following equation:

$\frac{\text { Peak area of products }}{\text { Peak area of nhep } \tan e} \times \frac{0.68 g}{1 g} \times 100$
$=$ Yield of hydrocarbons in $w t \%$

Using $\mathrm{Ni} / \mathrm{SiO} 2$ as a catalyst led to a gasification of $4.1 \%$ of the lignin. On the contrary, $23 \%$ liquid phase products were obtained. Among these, $20 \%$ consisted of monocyclic alcohols and $80 \%$ of monocyclic alkanes. Only the $\mathrm{Ni} / \mathrm{SiO} 2$ catalyst was able to recover monocyclic alcohols. For Ni/ HZSM-5, a gas yield of 5.5\% and a liquid products yield of $28 \%$ were generated. A total of roughly $90 \%$ monocyclic alkanes were recovered. Compared with the other catalysts which were used, the highest quantity of monocyclic alkanes was produced. The remaining $10 \%$ of the liquid products consisted of bicyclic alkanes. The reaction catalyzed with $\mathrm{Ni} / \mathrm{HBEA}$ showed the highest yields of both gas phase products with $6.8 \%$ and liquid phase products with $35 \%$. The reaction catalyzed with $\mathrm{Ni} / \mathrm{HBEA}$ showed the highest yields of both gas phase products with $6.8 \%$ and liquid phase products with $35 \%$. It was possible to obtain $83 \%$ of monocyclic alkanes and $17 \%$ of bicyclic alkanes. Therewith, the largest amount of bicyclic alkanes could be recovered.

The experiments demonstrated that zeolite-based nickel catalysts are suitable for lignin degradation and that it is possible to recover a large amount of monocyclic alkanes. Based on the results obtained, it is assumed that the HZSM-5 prevents the alkylation process of aromatic monomers due to its medium-sized pores. This can be explained by the fact that alcohols or olefins are formed during hydrogenation. This in turn leads to a low yield of bicyclic alkanes when HZSM-5 is used.

Furthermore, it was examined to what degree the temperature during catalysis impacts on the yield and the selectivity. For this purpose, the catalytic reaction with Ni/ HBEA catalyst was carried out at different temperatures with the same reaction conditions as above described. The results are recorded in Table 8. In general, it was observed that with higher temperature, both the hydrocarbon yield and the product selectivity increased. Simultaneously, the amount of unconverted lignin and solid residue decreased. This outcome can be explained by the fact that at higher temperatures, the hydrogenation of phenols is accelerated. Therefore, a larger quantity of lignin is converted.

\section{Zeolite Catalyst}

In a series of experiments involving the depolymerization of kraft lignin, various catalysts were tested regarding their efficiency. The two low-cost catalysts $\mathrm{Ni}_{10 \%}$ /zeolite and FHUDS-2 (a W-Mo-Ni industrial catalyst) were tested for their efficiency, and their performance was compared with that of a high-cost Ru catalyst (Table 9).

For this purpose, $5 \mathrm{~g}$ of the kraft lignin, $0.5 \mathrm{~g}$ of the nickel-based catalyst, $3 \mathrm{~mL}$ of formic acid and $30 \mathrm{~mL}$ of a $1: 1 \mathrm{v} / \mathrm{v}$ water-EtOH solution were added to a reactor (Huang et al. 2017a). Subsequently, the reactor was purged 3 times with nitrogen. Afterward, the reactor was heated at a rate of $10{ }^{\circ} \mathrm{C}$ per minute to temperatures between 200 and $300{ }^{\circ} \mathrm{C}$ at a pressure of $2 \mathrm{MPa} \mathrm{N}_{2}$. The reactor was then purged 3 times with nitrogen. The stirring speed during this process was $290 \mathrm{rpm}$. After 1 to $3 \mathrm{~h}$, the reaction was terminated by cooling the reactor in an ice bath. The resulting gases were analyzed by micro-GC. The solid residue was obtained from the liquid phase by filtration and vacuum drying overnight. The solid residue was later incubated in an oven at $105^{\circ} \mathrm{C}$ for $24 \mathrm{~h}$. The same procedure was performed using the $\mathrm{Ru}$ catalyst. However, instead of $0.5 \mathrm{~g}$, only $0.25 \mathrm{~g}$ of catalyst was used. Since noble metal catalysts tend to have a higher activity than metal catalysts such as nickel-based catalysts. In addition, the catalyst is considerably more expensive.

The catalysts were compared with regard to their yield in terms of lignin depolymerization and solid residue. Initially, no catalyst was used. A large part of the lignin was still depolymerized, even though no catalyst was present. It

Table 8 Analysis of products formed by Ni-catalyzed organosolv lignin conversion in $\mathrm{n}$-hexadecane at different temperatures (Kasakov et al. 2015)

\begin{tabular}{llllll}
\hline $\begin{array}{l}\text { Tem- } \\
\text { perature } \\
{[\mathrm{K}]}\end{array}$ & $\begin{array}{l}\text { Hydro- } \\
\text { carbons } \\
{[\mathrm{wt} \%]}\end{array}$ & $\begin{array}{l}\text { Selec- } \\
\text { tivity } \\
{[\mathrm{C} \%]}\end{array}$ & Water [wt\%] & $\begin{array}{l}\text { Solid } \\
\text { residue } \\
{[\mathrm{wt} \%]}\end{array}$ & $\begin{array}{l}\text { Unconv. } \\
\text { Lignin } \\
{[\mathrm{wt} \%]}\end{array}$ \\
\hline 493 & $29 \pm 2$ & 40 & 10 & $31 \pm 5$ & 26 \\
523 & $42 \pm 4$ & 57 & 18 & $22 \pm 5$ & 12 \\
543 & $44 \pm 4$ & 60 & 18 & $23 \pm 5$ & 11 \\
573 & $60 \pm 5$ & 82 & 19 & $11 \pm 5$ & 4 \\
593 & $70 \pm 5$ & 96 & 21 & $4 \pm 5$ & 0.1 \\
\hline
\end{tabular}


Table 9 Yields of depolymerized lignin and solid residue products and molecular weight and distribution of depolymerized lignin in depolymerization of Kraft lignin over various catalysts at different temperatures (Huang et al. 2017)

\begin{tabular}{|c|c|c|c|c|c|c|c|}
\hline \multirow[t]{2}{*}{ Catalyst } & \multirow{2}{*}{$\begin{array}{l}\text { Tempera- } \\
\text { ture }\left[{ }^{\circ} \mathrm{C}\right]\end{array}$} & \multicolumn{2}{|l|}{ Yield (wt $\%) 1$} & \multicolumn{3}{|l|}{ GPC results } & \multirow{2}{*}{$\begin{array}{l}\text { Reactor pressure } \\
(\mathrm{MPa})\end{array}$} \\
\hline & & Solid residue & Depolymerized lignin & $\mathrm{Mn}(\mathrm{g} / \mathrm{mol})$ & Mw (g/mol) & PDI (Mw/Mn) & \\
\hline Kraft lignin & - & - & - & $\sim 5000$ & $\sim 10,000$ & $\sim 2.0$ & - \\
\hline None & 200 & $4.7( \pm 1.7)$ & $88.9( \pm 3.5)$ & 900 & 6120 & 6.8 & $3.4-4.1$ \\
\hline FHUDS-2 & 200 & $7.7( \pm 3.0)$ & $91.8( \pm 3.0)$ & 900 & 6180 & 6.8 & $3.8-4.1$ \\
\hline $\mathrm{Ru}_{5 \% /} \mathrm{C}$ & 200 & $14.8( \pm 2.7)$ & $82.5( \pm 2.5)$ & 930 & 3640 & 3.9 & $3.8-5.5$ \\
\hline $\mathrm{Ni}_{10 \%} /$ Zeolite & 200 & $9.3( \pm 2.3)$ & $93.5( \pm 4.1)$ & 700 & 3150 & 4.3 & $4.1-5.2$ \\
\hline None & 250 & $0.1( \pm 0.0)$ & $92.7( \pm 2.1)$ & 850 & 3390 & 4.0 & $5.9-7.2$ \\
\hline FHUDS-2 & 250 & $5.3( \pm 1.4)$ & $84.0( \pm 5.8)$ & 810 & 3450 & 4.2 & $5.9-8.6$ \\
\hline $\mathrm{Ru}_{5 \%} / \mathrm{C}$ & 250 & $6.7( \pm 0.3)$ & $83.9( \pm 3.0)$ & 850 & 3340 & 3.9 & $6.2-9.3$ \\
\hline $\mathrm{Ni}_{10 \% /}$ Zeolite & 250 & $5.7( \pm 0.2)$ & $93.5( \pm 3.3)$ & 710 & 2540 & 3.6 & $5.9-6.9$ \\
\hline None & 300 & $0.6( \pm 0.3)$ & $88.0( \pm 2.1)$ & 410 & 1270 & 3.1 & 12.0 \\
\hline FHUDS-2 & 300 & $2.3( \pm 0.1)$ & $86.0( \pm 0.0)$ & 390 & 1080 & 2.7 & 12.0 \\
\hline $\mathrm{Ru}_{5 \% /} \mathrm{C}$ & 300 & $2.2( \pm 1.5)$ & $85.7( \pm 2.8)$ & 550 & 1060 & 2.0 & 12.0 \\
\hline $\mathrm{Ni}_{10 \%} /$ Zeolite & 300 & $0.2( \pm 0.0)$ & $89.4( \pm 3.5)$ & 420 & 900 & 2.1 & 12.0 \\
\hline
\end{tabular}

can be concluded that the solvents used, formic acid and the water-EtOH mixture, can cause effective depolymerization of lignin at temperatures of $200-300{ }^{\circ} \mathrm{C}$. All catalysts had almost no effect on the depolymerization as well as on the solid residue yield. This was observed at all temperatures. However, the use of catalysts showed effects on the reduction of the molecular mass with regard to the depolymerization yield as well as an increase in the molecular mass regarding the solid residue yield. This could presumably be due to the fact that the acidity of zeolites triggers a condensation of lignin on the surface of the catalyst. This effect was particularly evident at lower temperatures. The $\mathrm{Ni}_{10 \%} /$ zeolite cold catalyst achieved the best results. For example, at $200{ }^{\circ} \mathrm{C}$, the molecular mass was reduced to $3150 \mathrm{~g} / \mathrm{mol}$ from $10000 \mathrm{~g} / \mathrm{mol}$. The FHUDS-2 catalyst, on the other hand, achieved only $6180 \mathrm{~g} / \mathrm{mol}$ and the $\mathrm{Ru}_{5 \%} / \mathrm{C} 3640 \mathrm{~g} /$ mol. The increase in the temperature shows an increase in the solid residue yield in all experiments; therefore, it can be assumed that the depolymerization is thermodynamically better at higher temperatures (Huang et al. 2017a).

In addition, the gas yield at different temperatures was also investigated with regard to the catalysts. The results are summarized in Table 10. It can be observed that the use of the Ru catalyst causes an increase in the production of the gases $\mathrm{H}_{2}$ and $\mathrm{CO}_{2}$. The increase in temperature also increases this effect. The lowest yields of the gases $\mathrm{H}_{2}$ and $\mathrm{CO}_{2}$ were recorded with the Ni/zeolite catalyst. It is noteworthy that almost no $\mathrm{CO}_{2}$ was produced, regardless of the temperature. This could be attributed to the fact that nickel and zeolite cause extremely strong adsorption to hydrogen and carbon dioxide.

\section{Catalytic fast pyrolysis with ZSM-5 zeolites yields}

When using zeolite-based catalysts, the $\mathrm{SiO}_{2} / \mathrm{Al}_{2} \mathrm{O}_{3}$ ratio of the respective catalyst plays a major role in terms of catalytic efficiency. Among other things, the ratio indicates the acid content of the catalyst. The following study dealt with this matter. For this purpose, the same experiment was carried out using differently desilicated catalysts. The properties of the catalysts are listed in Table 11. Lignin, which was obtained from birch wood powder, was used. In each case, $1 \mathrm{~g}$ of the ZSM5 zeolite catalyst (zeolite catalyst with an orthorhombic framework) was heated with $10 \mathrm{~mL}$ of $\mathrm{NaOH}$ solution at a temperature of $70{ }^{\circ} \mathrm{C}$ for a period of $2 \mathrm{~h}$ ( $\mathrm{Li}$ et al. 2014). It should be noted that concentrations of $0.1-0.5 \mathrm{~mol}$ were used in the $\mathrm{NaOH}$ solution to ensure a different degree of desilication of the zeolite. The catalysts

Table 10 Yields of gas products from the KL depolymerization at various temperatures (Huang et al. 2017)

\begin{tabular}{llrll}
\hline Catalyst & $\begin{array}{l}\text { Temperature } \\
{\left[{ }^{\circ} \mathrm{C}\right]}\end{array}$ & \multicolumn{2}{c}{ Yield of gases (mol/mol-FA) } \\
\cline { 3 - 5 } & & $\mathrm{H}_{2}$ & $\mathrm{CO}$ & $\mathrm{CO}_{2}$ \\
\hline None & 300 & 0.19 & 0.04 & 0.27 \\
& 250 & 0.14 & 0.04 & 0.15 \\
& 200 & $<0.01$ & $\sim 0$ & 0.02 \\
Ru5\%/C & 300 & 0.31 & 0.01 & 0.44 \\
& 250 & 0.24 & $\sim 0$ & 0.27 \\
& 200 & 0.23 & $<0.01$ & 0.25 \\
Ni10\%/Zeolite & 300 & 0.05 & 0.15 & $\sim 0$ \\
& 250 & 0.05 & 0.03 & $\sim 0$ \\
& 200 & 0.01 & $<0.01$ & $\sim 0$ \\
\hline
\end{tabular}


were then filtered and washed three times with deionized water. They were afterward dried overnight at a temperature of $110^{\circ} \mathrm{C}$. The catalysts were then treated with $1 \mathrm{M}$ deionized water. This was followed by treatment with $1 \mathrm{M}$ $\mathrm{NH}_{4} \mathrm{NO}_{3}$ solution at $80{ }^{\circ} \mathrm{C}$, which replaced the zeolite ions. This was subsequently followed by drying again at $110^{\circ} \mathrm{C}$ overnight. The catalysts then had to be calcined at $550{ }^{\circ} \mathrm{C}$ for $10 \mathrm{~h}$. This resulted in an exchange of $\mathrm{Na}^{+}$for $\mathrm{H}^{+}(\mathrm{Li}$ et al. 2014). For the upcoming catalytic fast pyrolysis, the zeolite catalysts had to be calcined at $550{ }^{\circ} \mathrm{C}$ for $5 \mathrm{~h}$ in a muffle furnace. After that the zeolite catalysts could be mixed with the biomass in a ratio of 10:1, so that the pyrolysis could be carried out in a semi-batch reactor. $4 \mathrm{mg}$ each of the catalyst biomass mixture was used for this purpose. During the fast pyrolysis, the temperature was heated to $650^{\circ} \mathrm{C}$. Helium was also used as the gas. After the pyrolysis was completed, the resulting products were analyzed using a gas chromatograph (Li et al. 2014). The selectivity of the desanded aromates was given as moles of carbon in the product in relation to the total moles of aromatic carbon. The following equation was used for the calculation: addition, lower coke yields were achieved. This indicates that the desilicated zeolites exhibit a higher catalytic activity in the conversion of oxygenates to aromatics. This improvement can be explained, on the one hand, by the fact that the density of the Brønsted acid sites in the zeolites decreases as a result of the desilication, whereas the accessibility of the acid sites increases ( $\mathrm{Li}$ et al. 2014). Excessive desilication, such as was the case when the zeolite was treated with $0.5 \mathrm{M}$ $\mathrm{NaOH}$ solution, led to an increase in mesoporosity and a decrease in the microporosity of the zeolite, which worsens the diffusion path. As a result, the conversion of biomassderived oxygenates to aromatics is poorer ( $\mathrm{Li}$ et al. 2014).

\section{Effect of desilication on ZSM-5 zeolite and in catalytic fast pyrolysis}
13. Benzene.
29. Toluene.
30. Ethylbenzene.
31. p,m-Xylene.
32. o-Xylene.

Carbon yield $[\%]=\frac{w \mathrm{t} \text {. of compound } \times \text { mass fraction of carbon in each compound }}{\text { wt. of biomass } \times \text { mass fraction of carbon in biomass }} \times 100[\%]$

The results of the pyrolysis are shown in Table 12. In addition, Table 11 shows that the alkaline treatment caused structural changes in the catalysts. Thus, it can be observed that the $\mathrm{SiO}_{2} / \mathrm{Al}_{2} \mathrm{O}_{3}$ ratio of the zeolites decreased with increasing concentration of the $\mathrm{NaOH}$ solution used for the alkali treatment. The Si molecules were thus removed from the zeolite. The original zeolite catalyst has a comparatively high Brønsted acidity and much fewer Lewis acid sites ( $\mathrm{Li}$ et al. 2014). Exposure to $\mathrm{NaOH}$ significantly reduced the amount of Brønsted acid sites on the zeolites. In addition, it is assumed that mesopores were also formed which additionally enhanced the catalytic activity, since the diffusion path was improved. The results show that a higher yield of phenols and aromatics was achieved by desilication. In
33. 1,2,3-Trimethylbenzene.

34. Indene.

35. Naphthalene.

36. 2-Methylnaphthalene.

37. 1-Methylnaphthalene.

38. 1,7-Dimethylnaphthalene.

39. 2,6-Dimethylnaphthalene.

40. 1,8-Dimethylnaphthalene.

41. Anthracene.

In the subsequent experiment, pyrolysis was used to induce depolymerization. Since this involves breaking down the source materials lignin and the crude biomass into larger fractions which are often too large to fit into the existing pores of the zeolite catalyst, which is why the aim of the

Table 11 Characterization of the parent and desilicated ZSM-5 zeolites (Li et al. 2014)

\begin{tabular}{|c|c|c|c|c|c|c|c|c|c|}
\hline Catalyst & $\mathrm{SiO}_{2} / \mathrm{Al}_{2} \mathrm{O}_{3}$ & $\mathrm{~S}_{\mathrm{BET}}\left[\mathrm{m}^{2} / \mathrm{g}\right]$ & Smicro $\left[\mathrm{m}^{2} / \mathrm{g}\right]$ & Sext $[\mathrm{m} 2 / \mathrm{g}]$ & Vtotal $[\mathrm{mL} / \mathrm{g}]$ & $\begin{array}{l}\text { Vmicro } \\
{[\mathrm{mL} / \mathrm{g}]}\end{array}$ & $\begin{array}{l}\text { Vmeso } \\
{[\mathrm{mL} / \mathrm{g}]}\end{array}$ & $\begin{array}{l}\text { ABron- } \\
\text { sted } \\
[\mu \mathrm{mol} / \mathrm{g}])\end{array}$ & $\begin{array}{l}\text { ALewis } \\
[\mu \mathrm{mol} / \mathrm{g}])\end{array}$ \\
\hline $\begin{array}{l}\text { ZSM-5-PAR- } \\
\text { ENT }\end{array}$ & 25.5 & 406.8 & 379.7 & 27.1 & 0.222 & 0.164 & $0,000,000,000$ & 424.2 & 68.9 \\
\hline ZSM-5-0.1 M & 25.5 & 400.5 & 376.3 & 27.2 & 0.222 & 0.158 & 0.064 & 301.5 & 93.2 \\
\hline ZSM-5-0.2 M & 25.0 & 376.9 & 319.6 & 57.3 & 0.239 & 0.133 & 0.106 & 260.3 & 97.0 \\
\hline ZSM-5-0.3 M & 24.0 & 363.1 & 304.3 & 58.8 & 0.260 & 0.133 & 0.127 & 224.2 & 104.5 \\
\hline ZSM-5-0.4 M & 21.6 & 361.1 & 285.3 & 75.8 & 0.293 & 0.126 & 0.167 & 218.8 & 124.7 \\
\hline ZSM-5-0.5 M & 21.1 & 370.7 & 263.4 & 107.3 & 0.326 & 0.116 & 0.210 & 195.6 & 136.8 \\
\hline
\end{tabular}


Table 12 Product distributions in CFP of beech wood, cellulose, and lignin with parent and desilicated ZSM-5 zeolites (Li et al. 2014)

\begin{tabular}{|c|c|c|c|c|c|c|c|c|c|c|}
\hline \multirow[t]{2}{*}{ Product } & \multicolumn{6}{|c|}{ CFP of beech wood } & \multicolumn{2}{|c|}{ CFP of cellulose } & \multicolumn{2}{|c|}{ CFP of lignin } \\
\hline & Parent & $0.1 \mathrm{M}$ & $0.2 \mathrm{M}$ & $0.3 \mathrm{M}$ & $0.4 \mathrm{M}$ & $0.5 \mathrm{M}$ & Parent & $0.3 \mathrm{M}$ & Parent & $0.3 \mathrm{M}$ \\
\hline \multicolumn{11}{|c|}{ Carbon yield [\%] } \\
\hline Aromatics & $\begin{array}{l}23.7 \\
\pm \\
0.5\end{array}$ & $\begin{array}{l}26.9 \\
\pm \\
0.2\end{array}$ & $\begin{array}{l}29.0 \\
\pm \\
0.8\end{array}$ & $\begin{array}{l}30.1 \\
\pm \\
0.6\end{array}$ & $\begin{array}{l}28.6 \\
\pm \\
0.2\end{array}$ & $\begin{array}{l}26.2 \\
\pm \\
0.5\end{array}$ & $\begin{array}{l}31.1 \\
\pm \\
0.5\end{array}$ & $\begin{array}{l}32.1 \\
\pm \\
0.2\end{array}$ & $\begin{array}{l}9.89 \\
\pm \\
0.23\end{array}$ & $\begin{array}{l}13.2 \\
\pm \\
0.1\end{array}$ \\
\hline Olefins & $\begin{array}{l}3.11 \\
\pm \\
0.30\end{array}$ & $\begin{array}{l}2.78 \\
\pm \\
0.54\end{array}$ & $\begin{array}{l}2.52 \\
\pm \\
0.32\end{array}$ & $\begin{array}{l}2.59 \\
\pm \\
0.10\end{array}$ & $\begin{array}{l}3.43 \\
\pm \\
0.03\end{array}$ & $\begin{array}{l}4.15 \\
\pm \\
0.08\end{array}$ & $\begin{array}{l}1.27 \\
\pm \\
0.04\end{array}$ & $\begin{array}{l}1.88 \\
\pm \\
0.28\end{array}$ & $\begin{array}{l}1.08 \\
\pm \\
0.1\end{array}$ & $\begin{array}{l}1.55 \\
\pm \\
0.01\end{array}$ \\
\hline Phenols & $\begin{array}{l}0.32 \\
\pm \\
0.01\end{array}$ & $\begin{array}{l}0.32 \\
\pm \\
0.01\end{array}$ & $\begin{array}{l}0.36 \\
\pm \\
0.02\end{array}$ & $\begin{array}{l}0.35 \\
\pm \\
0.01\end{array}$ & $\begin{array}{l}0.50 \\
\pm \\
0.01\end{array}$ & $\begin{array}{l}0.38 \\
\pm \\
0.02\end{array}$ & 0 & 0 & $\begin{array}{l}0.85 \\
\pm \\
0.04\end{array}$ & $\begin{array}{l}1.17 \\
\pm \\
0.01\end{array}$ \\
\hline $\mathrm{CO}$ & $\begin{array}{l}20.4 \\
\pm \\
0.4\end{array}$ & $\begin{array}{l}20.7 \\
\pm \\
0.2\end{array}$ & $\begin{array}{l}20.1 \\
\pm \\
0.0\end{array}$ & $\begin{array}{l}19.3 \\
\pm \\
0.2\end{array}$ & $\begin{array}{l}18.6 \\
\pm \\
0.5\end{array}$ & $\begin{array}{l}18.9 \\
\pm \\
0.2\end{array}$ & $\begin{array}{l}27.8 \\
\pm \\
0.2\end{array}$ & $\begin{array}{l}28.6 \\
\pm \\
0.2\end{array}$ & $\begin{array}{l}3.93 \\
\pm \\
0.17\end{array}$ & $\begin{array}{l}5.20 \\
\pm \\
0.02\end{array}$ \\
\hline $\mathrm{CO}_{2}$ & $\begin{array}{l}6.17 \\
\pm \\
0.16\end{array}$ & $\begin{array}{l}5.65 \\
\pm \\
0.04\end{array}$ & $\begin{array}{l}5.90 \\
\pm \\
0.04\end{array}$ & $\begin{array}{l}5.98 \\
\pm \\
0.16\end{array}$ & $\begin{array}{l}6.12 \\
\pm \\
0.19\end{array}$ & $\begin{array}{l}6.40 \\
\pm \\
0.09\end{array}$ & $\begin{array}{l}7.03 \\
\pm \\
0.1\end{array}$ & $\begin{array}{l}7.38 \\
\pm \\
0.05\end{array}$ & $\begin{array}{l}2.80 \\
\pm \\
0.02\end{array}$ & $\begin{array}{l}3.26 \\
\pm \\
0.02\end{array}$ \\
\hline Coke & $\begin{array}{l}44.2 \\
\pm \\
0.1\end{array}$ & $\begin{array}{l}41.3 \\
\pm \\
0.2\end{array}$ & $\begin{array}{l}40.2 \\
\pm \\
0.1\end{array}$ & $\begin{array}{l}39.9 \\
\pm \\
0.3\end{array}$ & $\begin{array}{l}41.4 \\
\pm \\
0.6\end{array}$ & $\begin{array}{l}41.8 \\
\pm \\
0.1\end{array}$ & $\begin{array}{l}28.8 \\
\pm \\
0.1\end{array}$ & $\begin{array}{l}28.4 \\
\pm \\
0.2\end{array}$ & $\begin{array}{l}61.5 \\
\pm \\
0.4\end{array}$ & $\begin{array}{l}54.7 \\
\pm \\
0.2\end{array}$ \\
\hline \multicolumn{11}{|c|}{ Aromatic selectivity [\%] } \\
\hline Benzene & 12.3 & 13.3 & 12.1 & 12.2 & 12.5 & 12.7 & 16.5 & 17.2 & 19.5 & 18.1 \\
\hline Toluene & 28.6 & 30.3 & 26.5 & 27.2 & 27.5 & 29.8 & 26.1 & 28.4 & 26.6 & 24.7 \\
\hline Xylenes & 23.0 & 22.2 & 24.5 & 25.8 & 25.2 & 28.7 & 14.4 & 15.3 & 15.8 & 16.3 \\
\hline Alkylbenzene & 2.8 & 2.3 & 3.5 & 3.7 & 3.5 & 4.6 & 2.8 & 2.7 & 1.8 & 2.1 \\
\hline Indanes & 2.8 & 2.5 & 2.8 & 2.7 & 2.9 & 2.8 & 3.5 & 3.8 & 2.8 & 3.2 \\
\hline Naphthalenes & 30.5 & 29.5 & 30.5 & 28.4 & 28.5 & 21.4 & 36.6 & 32.6 & 33.4 & 35.6 \\
\hline
\end{tabular}

experiment is to investigate whether the catalytic activity can be improved by creating additional mesopores in the zeolite catalyst (Hoff et al. 2017). In order to achieve this, two pyrolysis experiments were carried out, one using a ZSM-5 catalyst and the other using a ZSM-5 catalyst previously treated with a $0.2 \mathrm{M} \mathrm{NaOH}$ solution. The $\mathrm{NaOH}$ treatment caused the formation of mesopores on the catalyst surface (Hoff et al. 2017). To accomplish this, a micro-pyrolyzer equipped with an auto-shot sampler was used. The biomass and the zeolite catalyst were first mixed in a ratio of 1:20 (Hoff et al. 2017). Then, $5 \mathrm{mg}$ of each mixture was added to the pyrolysis furnace. The furnace was preheated to $550{ }^{\circ} \mathrm{C}$ beforehand. Subsequently, the vapor generated during pyrolysis was sucked into the gas chromatograph by using helium, and the gases were subsequently separated. The pyrolysis gas was analyzed using a mass spectrometer detector (MSD) or a flame ionization detector (FID) (Hoff et al. 2017). The results of the experiment were defined as follows. Product distribution was reported as molar carbon yield, which was defined as the molar ratio of carbon in a certain product to carbon in the starting material. The selectivity for aromatics was specified as moles of carbon in a distinct aromatic hydrocarbon in relation to the overall moles of carbon present in the fluid products. Desilication of the zeolite catalyst was performed by mixing $2 \mathrm{~g}$ of the ZSM-5 catalyst with a $\mathrm{SiO}_{2} / \mathrm{Al}_{2} \mathrm{O}_{3}$ ratio of 23 with $50 \mathrm{~mL}$ of $\mathrm{NaOH}$ solution in a $125-\mathrm{mL}$ Nalgene flask. The flask was heated in an oil bath at $65{ }^{\circ} \mathrm{C}$ for $75 \mathrm{~min}$. Meanwhile, the solution was stirred at $500 \mathrm{rpm}$ using a magnet. The reaction was then terminated by cooling the flask in an ice bath for $10 \mathrm{~min}$. The mixture was then centrifuged for $30 \mathrm{~min}$. The obtained solid was rinsed with deionized water so that the liquid phase reached a $\mathrm{pH}$ value of 9 . The sample was then stored in $50 \mathrm{~mL}$ of $0.1 \mathrm{M} \mathrm{HCl}$ solution at $65^{\circ} \mathrm{C}$ for $4 \mathrm{~min}$ (Hoff et al. 2017). The sample was subsequently rinsed once more with deionized water until the $\mathrm{pH}$ of the fluid equaled 5. Next, the sample was stored in $100 \mathrm{~mL}$ of $0.2 \mathrm{M} \mathrm{NH}_{4} \mathrm{NO}_{3}$ solution overnight. Finally, the samples were exposed to calcination at $550{ }^{\circ} \mathrm{C}$ for $10 \mathrm{~h}$. The $\mathrm{N}_{2}$ adsorption-desorption isotherms based on which the pore size distribution, the total surface area and the micro- and mesopores were determined were measured by Micromeritics ASAP 2020 system at $77 \mathrm{~K}$. The $\mathrm{N}_{2}$ adsorption-desorption isotherms based on which the pore size distribution, the total surface area and the micro- and mesopores were determined were measured by Micromeritics ASAP 2020 system at $77 \mathrm{~K}$. To investigate the $\mathrm{SiO}_{2} /$ $\mathrm{Al}_{2} \mathrm{O}_{3}$ ratio, energy dispersive $\mathrm{X}$-ray spectroscopy (EDS) was performed with an AztecTM spectrometer system (Hoff 
et al. 2017). The results on the catalyst properties are given in Table 13. Characterization of Brønsted and Lewis acid sites was performed by using $\mathrm{NH}_{3}$ desorption (NH3-TPD) and diffuse reflectance infrared Fourier transform spectroscopy (DRIFTS) (Hoff et al. 2017). This was done for various temperatures. The results are given in Table 14. Experimental data of the pyrolysis test are given in Table 15. The results of the experiment showed that for lignin, the $0.2 \mathrm{M}$ catalyst reduced the aromatics yield and that in the case of pyrolysis of red oak, the aromatics yield was increased.

The selectivity of the pyrolysis products can be controlled by the choice of a compatible catalyst. The ZSM-5 catalyst is excellently suited for this purpose, since it allows the highest selectivity for monocyclic platform aromatics to be achieved. However, despite this, a large portion of the carbon of the feedstock is converted to coke or coal. These products are undesirable by-products whose production should be reduced. The formation of coke is promoted on the one hand by condensation reactions in which polyaromatic hydrocarbons are formed which take place in the micropores (Hoff et al. 2017). On the other hand, this is favored by the formation of smaller oxygen compounds which are polymerized on the outer surface of the zeolite. Furthermore, it has been shown that during pyrolysis, up to $30 \%$ of the carbon is lost due to the above-mentioned processes (Hoff et al. 2017). The formation of coke can be reduced to a large extent by improving the diffusion as well as by more easily accessible bulk acid sites. This also leads to a better product selectivity. The performance of a catalyst is limited by insufficient diffusion pathways. When the pores are widened, the diffusion rate is immediately improved, increasing the catalytic activity for many reactions (Hoff et al. 2017). In addition, the formation of an outer film can restrict mass transfer by up to $60 \%$. Therefore, desilication is a suitable method to promote intracrystalline diffusion and mass transfer, thus making the active sites more accessible. For ZSM-5 catalysts, the aluminum concentration has to be taken into account. Zeolite catalysts, which have a fairly high aluminum content, are
Table 14 Acid site densities for $\mathrm{NaOH}$ desilicated samples calculated from Fourier transform infrared spectra collected for various desorption temperatures (Hoff et al. 2017)

\begin{tabular}{lllll}
\hline & $150{ }^{\circ} \mathrm{C}$ & & $250{ }^{\circ} \mathrm{C}$ & $350{ }^{\circ} \mathrm{C}$ \\
\cline { 2 - 3 } & $\begin{array}{l}\text { Brønsted } \\
{\left[\mu \mathrm{mol} \mathrm{g}{ }^{-1}\right]}\end{array}$ & $\begin{array}{l}\text { Lewis } \\
{\left[\mu \mathrm{mol} \mathrm{g} \mathrm{g}^{-1}\right]}\end{array}$ & $\begin{array}{l}\text { Brønsted } \\
{\left[\mu \mathrm{mol} \mathrm{g} \mathrm{g}^{-1}\right]}\end{array}$ & $\begin{array}{l}\text { Brønsted } \\
{\left[\mu \mathrm{mol} \mathrm{g}{ }^{-1}\right]}\end{array}$ \\
\hline $\begin{array}{c}\text { Commercial } \\
\text { catalyst }\end{array}$ & 650 & 28 & 655 & 582 \\
$0.2 \mathrm{M} \mathrm{NaOH}$ & 958 & 24 & 917 & 715 \\
\hline
\end{tabular}

quite resistant to the alkaline treatment (Hoff et al. 2017). This can cause structural changes in the ZSM- 5 catalyst, which in turn can have a serious effect on the reaction and product selectivity. Among other things, the yield of aromatic products can be reduced by up to $50 \%$ (Hoff et al. 2017).

The experiment demonstrated that the zeolite catalyst was desilicated by $\mathrm{NaOH}$, resulting in an increase in the mesoporosity. In the fast pyrolysis of cellulose, lignin and red oak it became evident that only in the pyrolysis of cellulose by the treated catalyst an improvement in the mesoporosity could be achieved. It was found that especially in the pyrolysis of lignin and red oak, a catalytic improvement was achieved by the desilicated catalyst. It is assumed that this is related to a simplified diffusion and a more efficient mass transport. The alkali treatment, besides creating mesopores, needs to facilitate Brønsted acid sites, so that the deoxygenation and conversion of bulky reactants to aromatic hydrocarbons is enhanced (Hoff et al. 2017).

\section{Zeolite catalyst acidity and structure of ZSM-5}

The following study investigates the influence of the starting material as well as the acidity of a zeolite catalyst in the depolymerization of lignin by pyrolysis, which was also carried out at three different temperatures. The pyrolysis was performed
Table 13 Elemental composition and textural properties of the parent and desilicated ZSM-5 zeolites (Hoff et al. 2017)

\begin{tabular}{lllllll}
\hline & $\begin{array}{l}\mathrm{EDS} \mathrm{SiO}_{2} / \\
\mathrm{A} 2 \mathrm{BET} \mathrm{SA}^{\mathrm{a}}\end{array}$ & $\begin{array}{l}\left.\mathrm{BET}^{\mathrm{b}} / \mathrm{g}\right] \\
{\left[\mathrm{m}^{2}\right.}\end{array}$ & $\begin{array}{l}\mathrm{t}-\mathrm{Plot} \mu \text { Pore } \\
\mathrm{SA}^{\mathrm{c}}\left[\mathrm{m}^{2} / \mathrm{g}\right]\end{array}$ & $\begin{array}{l}\text { t-Plot Ext. } \\
\mathrm{SA}\left[\mathrm{m}^{2} / \mathrm{g}\right]\end{array}$ & $\begin{array}{l}\text { t-Plot } \mu \text { Pore } \\
\text { Vol. }^{\mathrm{c}}\left[\mathrm{cm}^{3} / \mathrm{g}\right]\end{array}$ & $\begin{array}{l}\text { Mesopore } \\
\begin{array}{l}\mathrm{Vol}^{\mathrm{d}} \\
{\left[\mathrm{cm}^{3} / \mathrm{g}\right]}\end{array}\end{array}$ \\
\hline Commercial Catalyst & 23.2 & 376 & 276 & 100 & 0.128 & 0.074 \\
$0.2 \mathrm{M} \mathrm{NaOH}$ & 23.6 & 409 & 277 & 133 & 0.128 & 0.123 \\
\hline
\end{tabular}

${ }^{\mathrm{a}} \mathrm{SiO}_{2} / \mathrm{Al}_{2} \mathrm{O}_{3}$ ratio determined by energy dispersive $\mathrm{X}$-ray spectroscopy analysis

${ }^{\mathrm{b}}$ Total surface area determined using the BET method

${ }^{c}$ External (Ext.) and micropore (micro-Pore) surface area and volume calculated using the t-plot method

${ }^{\mathrm{d}}$ Mesopore volume calculated from the total and microporous volumes determined by

$\mathrm{N}_{2}$ physisorption using the single-point adsorption pore volume (total) and t-plot

(micropore) methods 
Table 15 Aromatic yield and liquid products distribution obtained for the catalytic fast pyrolysis of cellulose, lignin, and red oak over commercial and $0.2 \mathrm{M} \mathrm{NaOH}$ desilicated ZSM-5 (Hoff et al. 2017)

\begin{tabular}{|c|c|c|c|c|c|c|}
\hline \multirow{2}{*}{$\begin{array}{l}\text { Aromatic yield } \\
{\left[\begin{array}{c}\%\end{array}\right]}\end{array}$} & \multicolumn{3}{|c|}{ Commercial zeolite } & \multicolumn{3}{|c|}{$0.2 \mathrm{M} \mathrm{NaOH}$} \\
\hline & Cellulose & Lignin & Red Oak & Cellulose & Lignin & Red oak \\
\hline & $28.5 \pm 0.5$ & $11.8 \pm 0.6$ & $23.9 \pm 0.7$ & $29.4 \pm 0.9$ & $7.7 \pm 0.8$ & $27.9 \pm 0.8$ \\
\hline \multicolumn{7}{|c|}{ Liquid product distribution } \\
\hline 13 & $18.3 \pm 0.1$ & $18.2 \pm 0.2$ & $14.0 \pm 0.1$ & $22.0 \pm 0.1$ & $17.0 \pm 0.4$ & $14.5 \pm 0.1$ \\
\hline 29 & $29.5 \pm 0.4$ & $25.0 \pm 0.4$ & $26.1 \pm 0.0$ & $30.1 \pm 0.2$ & $24.3 \pm 0.7$ & $26.1 \pm 0.1$ \\
\hline 30 & $0.9 \pm 0.0$ & $1.4 \pm 0.1$ & $1.3 \pm 0.0$ & $0.7 \pm 0.0$ & $1.5 \pm 0.2$ & $1.3 \pm 0.1$ \\
\hline 31 & $14.5 \pm 0.0$ & $18.4 \pm 0.3$ & $21.4 \pm 0.1$ & $12.6 \pm 0.2$ & $17.7 \pm 0.4$ & $20.9 \pm 0.1$ \\
\hline 32 & $4.1 \pm 0.0$ & $4.4 \pm 0.2$ & $5.9 \pm 0.0$ & $3.4 \pm 0.0$ & $5.0 \pm 0.1$ & $5.9 \pm 0.0$ \\
\hline 33 & $2.6 \pm 0.0$ & $1.7 \pm 1.2$ & $3.9 \pm 0.0$ & $1.7 \pm 0.0$ & $2.7 \pm 0.0$ & $3.5 \pm 0.1$ \\
\hline 34 & $0.2 \pm 0.0$ & $0 \pm 0.0$ & $1.3 \pm 0.1$ & $0.2 \pm 0.0$ & $2.0 \pm 0.1$ & $1.6 \pm 0.1$ \\
\hline 35 & $10.5 \pm 0.0$ & $15.0 \pm 0.4$ & $9.0 \pm 0.1$ & $12.7 \pm 0.2$ & $13.6 \pm 1.1$ & $9.2 \pm 0.0$ \\
\hline 36 & $10.4 \pm 0.0$ & $10.6 \pm 0.2$ & $9.1 \pm 0.2$ & $10.6 \pm 0.1$ & $9.4 \pm 0.5$ & $8.6 \pm 0.1$ \\
\hline 37 & $4.3 \pm 0.0$ & $0 \pm 0.0$ & $2.5 \pm 0.0$ & $5.0 \pm 0.0$ & $1.6 \pm 0.1$ & $2.7 \pm 0.0$ \\
\hline 38 & $1.7 \pm 0.0$ & $3.0 \pm 0.1$ & $3.2 \pm 0.2$ & $0.2 \pm 0.1$ & $2.9 \pm 0.1$ & $2.8 \pm 0.0$ \\
\hline 39 & $1.9 \pm 0.0$ & $0.1 \pm 0.0$ & $0.9 \pm 0.0$ & $0.1 \pm 0.0$ & $0.5 \pm 0.0$ & $1.1 \pm 0.0$ \\
\hline 40 & $0.6 \pm 0.0$ & $0 \pm 0.0$ & $0.2 \pm 0.2$ & $0.5 \pm 0.0$ & $0.4 \pm 0.0$ & $0.4 \pm 0.0$ \\
\hline 41 & $0.3 \pm 0.1$ & $1.2 \pm 0.0$ & $1.2 \pm 0.0$ & $0.2 \pm 0.0$ & $1.3 \pm 0.1$ & $1.4 \pm 0.0$ \\
\hline
\end{tabular}

with raw lignin as well as with torrefied lignin. In all experiments, the catalyst/feed ratio amounted to 1 to 4 (Adhikari et al. 2014). The ZSM-5 catalysts were calcined beforehand in order to obtain different acid contents. The catalysts were then mixed together with the respective lignin types in a ratio of 1:4. The pyrolysis gas used was helium (Adhikari et al. 2014). The gas resulting from the pyrolysis was then transferred to a gas chromatograph. The liquid products were analyzed using an Agilent 7890 GC/5975 MS (Adhikari et al. 2014). The results of the experiment are shown in Table 16. The properties of the differently calcined catalysts are given in Table 17. Furthermore, the following equation was used to calculate the carbon yield:

carbonyield $[w t \%]=\left[\frac{\text { mass of each compound } \times \text { mass fraction of carbon in each compound }}{\text { mass of biomass } \times \text { mass fraction of carbon in biomass }}\right] \times 100[\%]$ increased. Regarding the temperature, it was found that only at lower temperatures, such as $500{ }^{\circ} \mathrm{C}$, the formation of guaiacols took place only using less acidic catalysts such as $Z_{80}$ and $Z_{280}$. From this, it can be concluded that ZSM-5 catalysts with higher acidity are more suitable for the cleavage of aromatic $\mathrm{C}-\mathrm{O}$ bonds in lignin. The highest yield of phenolic products was obtained with the $\mathrm{Z}_{280}$ catalyst. This catalyst exhibits the lowest acidity. In general, it was observed that due to the temperature deviations of the pyrolysis, there were only minor differences in the yield of aromatic products (Adhikari et al. 2014).

Subsequently, the same experiment was performed again using torrefied lignin as the starting material. In this
Untreated raw lignin was firstly used as the starting material. It was found that a large amount of hydrocarbons could be recovered by using a catalyst in all experiments. It can be concluded that the zeolite catalyst enhances the direct deoxygenation of methoxyphenols to aromatic hydrocarbons (Adhikari et al. 2014). In addition, the use of the catalyst enhances the formation of olefins. It can therefore be assumed that the aliphatic bonds in the lignin are increasingly broken. This is positive since olefins are converted into aromatic hydrocarbons by the aromatization reaction (Adhikari et al. 2014). With regard to the acidity of the catalyst, it was found that the formation of aromatic hydrocarbons was also boosted when the acidity case, likewise as in the pyrolysis of the raw lignin, mainly aromatic hydrocarbons were obtained. It was observed that the higher acid content of the catalyst increased the yield of aromatics. The use of catalyst $Z_{30}$, which has an extremely high acid content, also resulted in an increased phenol yield (Adhikari et al. 2014). Compared to crude lignin, hardly any guaiacols were formed during the pyrolysis of the torrefied lignin, even with the less acidic catalysts. It can therefore be assumed that the torrefaction process leads to structural differences that favor the deoxygenation efficiency of the zeolite catalyst. The experiment has demonstrated that the acidic zeolite catalysts (in particular the Brønsted acid sites) increase the cleavage of 
Table 16 Effect of the catalyst acidity and pyrolysis temperature on the product distribution of raw and torrefied lignin pyrolysis (Adhikari et al. 2014)

\begin{tabular}{|c|c|c|c|c|c|}
\hline \multirow[t]{2}{*}{ Catalyst } & \multirow[t]{2}{*}{ Material } & \multirow{2}{*}{$\begin{array}{l}\text { Temperature } \\
{\left[{ }^{\circ} \mathrm{C}\right]}\end{array}$} & \multicolumn{3}{|c|}{ Carbon yield [\%] } \\
\hline & & & Aromatics & Phenols & Guaiacols \\
\hline \multirow[t]{3}{*}{$\mathrm{Z}_{30}$} & \multirow[t]{3}{*}{ Raw lignin } & 500 & $22.4 \pm 0.45$ & 6.25 & - \\
\hline & & 550 & $21 \pm 1.25$ & $7.5 \pm 0.75$ & 1 \\
\hline & & 600 & $22.25 \pm 2.08$ & 9.16 & 1.5 \\
\hline \multirow[t]{3}{*}{$\mathrm{Z}_{50}$} & \multirow[t]{3}{*}{ Raw lignin } & 500 & $18.5 \pm 2.58$ & 2.5 & 0.5 \\
\hline & & 550 & $19.75 \pm 1.04$ & 4.16 & 0.83 \\
\hline & & 600 & $16.67 \pm 1.67$ & 2.91 & 1.58 \\
\hline \multirow[t]{3}{*}{$\mathrm{Z}_{80}$} & \multirow[t]{3}{*}{ Raw lignin } & 500 & $13,66 \pm 0.83$ & 0.416 & 3.16 \\
\hline & & 550 & $14.5 \pm 0.75$ & 2.08 & 0.416 \\
\hline & & 600 & $13.33 \pm 0.5$ & 1.67 & 0.416 \\
\hline \multirow[t]{3}{*}{$\mathrm{Z}_{280}$} & \multirow[t]{3}{*}{ Raw lignin } & 500 & $7.84 \pm 0,64$ & 3.75 & 1.75 \\
\hline & & 550 & 5.6 & 7.5 & 1 \\
\hline & & 600 & 7.24 & 4 & 0.5 \\
\hline \multirow[t]{3}{*}{$\mathrm{Z}_{30}$} & \multirow[t]{3}{*}{ Torrefied lignin } & 500 & $29 \pm 0.625$ & 2.25 & - \\
\hline & & 550 & $29.75 \pm 2.5$ & $8.75 \pm 1.25$ & 0.25 \\
\hline & & 600 & 35.75 & $11.25 \pm 0.625$ & 0.25 \\
\hline \multirow[t]{3}{*}{$\mathrm{Z}_{50}$} & \multirow[t]{3}{*}{ Torrefied lignin } & 500 & 24 & 2 & 0.5 \\
\hline & & 550 & $25 \pm 0.75$ & 2.5 & 0.125 \\
\hline & & 600 & $27 \pm 1$ & 2.7 & 0.125 \\
\hline \multirow[t]{3}{*}{$\mathrm{Z}_{80}$} & \multirow[t]{3}{*}{ Torrefied lignin } & 500 & $17 \pm 1.375$ & $1.5 \pm 0.625$ & 0.25 \\
\hline & & 550 & $11.25 \pm 1.25$ & 3.5 & 1 \\
\hline & & 600 & $19.5 \pm 1.125$ & $3 \pm 1.25$ & 0.5 \\
\hline \multirow[t]{3}{*}{$\mathrm{Z}_{280}$} & \multirow[t]{3}{*}{ Torrefied lignin } & 500 & 13.5 & 1.25 & 0.25 \\
\hline & & 550 & 8.75 & 2.5 & 0.75 \\
\hline & & 600 & $12.25 \pm 1.875$ & 5 & 1.5 \\
\hline
\end{tabular}

Table 17 Properties of different acidic zeolites (Adhikari et al. 2014)

\begin{tabular}{lllll}
\hline $\begin{array}{l}\text { Silica/alu- } \\
\text { mina } \\
\left(\mathrm{SiO}_{2} / \mathrm{Al}_{2} \mathrm{O}_{3}\right) \\
\text { ratio }\end{array}$ & $\begin{array}{l}\text { Geometric } \\
\text { mean particle } \\
\text { size }(\mu \mathrm{m})\end{array}$ & $\begin{array}{l}\text { Surface } \\
\text { area } \\
\left(\mathrm{m}^{2} / \mathrm{g}\right)\end{array}$ & Peak area & $\begin{array}{l}\text { Isopropylamine } \\
\text { absorption } \\
(\mu \mathrm{mol} / \mathrm{g})\end{array}$ \\
\hline $30\left(\mathrm{Z}_{30}\right)$ & 81.14 & 400 & $2803 \pm 41$ & 1384.36 \\
$50\left(\mathrm{Z}_{50}\right)$ & 87.32 & 425 & $2639 \pm 13$ & 1067.17 \\
$80\left(\mathrm{Z}_{80}\right)$ & 87.58 & 425 & $1742 \pm 78$ & 841.88 \\
$280\left(\mathrm{Z}_{280}\right)$ & 89.16 & 400 & $1222 \pm 33$ & 152.86 \\
\hline
\end{tabular}

bonds such as methoxyl units found in guaiacols (Adhikari et al. 2014). This is mainly due to the fact that they release protons, which allows the formation of aromatic compounds and phenols. The highest yields of aromatics were obtained with the particularly acidic catalysts $Z_{30}$ and $\mathrm{Z}_{50}$ at temperatures of $500{ }^{\circ} \mathrm{C}$ and $550{ }^{\circ} \mathrm{C}$, respectively. For the less acidic zeolite catalysts, on the other hand, no great difference was obtained due to the temperature difference. It can be concluded from the experiment that both the choice of starting material and the acidity of the catalyst have an impact on the product selectivity. Increased acidity and the torrefracturing process resulted in better yields of aromatics and phenols (Adhikari et al. 2014) (Scheme 6).

\section{H-ZSM-5 and H-beta comparison}

42. Acetic Acid.

43. Furfural.

44. Furfural alcohol.

45. Hydroxyacetone.

48. p-xylene.

49. o-xylene.

The following study compared the two zeolite acidic catalysts H-Beta and H-ZSM-5 with respect to their product selectivity. The different properties of the two catalysts are listed in Table 18. Different lignin-containing materials were used for this purpose. In addition, the effect of the acid content of the catalyst was also tested. For this purpose, a Frontier Lab Double-Shot micro-pyrolyzer PY-2020iD equipped with the Frontier Lab Auto-Shot Sampler AS-1020E was used (Mihalcik et al. 2011). This is also connected to a gas chromatograph. The products generated by the pyrolysis were identified by a mass spectrometer. About $1 \mathrm{~g}$ of the respective biomass with $5 \mathrm{mg}$ of the catalyst was added to the pyrolysis apparatus.

The results of the test in which the H-ZSM-5 catalyst was used are displayed in Table 19. It can be seen that the H-ZSM-5 catalyst performed best, as it significantly 


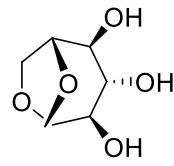

46

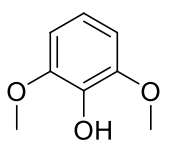

47
Scheme 6 Levoglucosan (46), Syringol (47)

minimized the oxygenated compounds. This can be observed with all the feedstocks used. The product selectivity, however, was significantly influenced by the feedstock. In general, the catalyst H-ZSM-5 (23) exhibits a strong bond cleavage property, which is why only very small amounts of hydroxyacetone (45), acetic acid (42) and syringol (47) could be identified. In addition, the best yield was obtained with aromatic hydrocarbon. Substituted benzenes and naphthalenes were increasingly abundant. Looking at the Si/Al ratios, it was found that the H-ZSM (280) catalyst generated the least aromatics, while the H-ZSM-5 (23) catalyst generated the most aromatics. It can be concluded that the acidity of the catalyst has a strong effect on the formation of aromatics (Mihalcik et al. 2011).

The results of the experiment in which H-beta catalysts are given in Table 20. It was found that in terms of aromatics yield, the H-beta catalysts produced a higher conversion than the H-ZSM $(50,280)$ catalysts for all feedstocks used.

The test demonstrated that all catalysts used were able to reduce the oxygen within the pyrolytic vapors. The H-ZSM-5 (23) catalyst showed the best results. This catalyst also achieved the highest yield of aromatics. This shows that the ratio of $\mathrm{Si}$ and $\mathrm{Al}$ has a significant effect on the catalytic activity. Since this enhances the properties to the deoxygenate, more aromatics could be obtained (Mihalcik et al. 2011).

\section{Cu-Mo doped zeolite ZSM-5 catalyzed conversion}

In this study, the three zeolite catalysts $\mathrm{Cu} / \mathrm{Mo}-\mathrm{ZSM}-5, \mathrm{Cu}-$ ZSM-5 and HZSM-5 were tested under different reaction conditions. This involved testing different water-MeOH ratios for the solvent. The properties of the individual catalysts are shown in Table 21. The results of the experiment are shown in Table 22. To accomplish this, $0.5 \mathrm{~g}$ each of lignin and $0.125 \mathrm{~g}$ of zeolite catalyst were heated with $60 \mathrm{ml}$ of $1.7 \mathrm{mmol} \mathrm{NaOH}$ solvent in a $100-\mathrm{ml}$ reactor at $220{ }^{\circ} \mathrm{C}$ for $7 \mathrm{~h}$ (Singh und Ekhe 2015). Prior to this, the reactor was purged with argon 3 to 5 times. After the reaction was terminated, the obtained products were washed with $20 \mathrm{~mL}$ of water. Subsequently, centrifugation was performed at $2500 \mathrm{rpm}$ for $15 \mathrm{~min}$. This allowed separation of the liquid and solid products. Ethyl acetate (EtOAc) was used to extract the reaction products present in the organic and aqueous phases (Singh und Ekhe 2015). The catalyst, the resulting char and fragments of lignin could not be dissolved in EtOAc (Singh und Ekhe 2015). The products dissolved in ethyl acetate were then analyzed qualitatively and quantitatively. The yields were calculated using the following equations:

$$
\begin{aligned}
& \text { Lignin Conversation }[\%] \\
& =\left[1-\frac{w(\text { EtOAc insolubale }- \text { catalyst used })}{w(\text { initial Lignin })}\right] \times 100[\%]
\end{aligned}
$$

EtOAc soluble products $[w t \%]=\frac{w(\text { EtOAc solubales })}{w(\text { initial Lignin })} \times 100[\%]$

$T H F$ soluble products $[w t \%]=\frac{w(\text { THF solubales })}{w(\text { initial Lignin })} \times 100[\%]$

$\operatorname{char}[\%]=\left[\frac{w(\text { THF insolubale })-w(\text { catalyst used })}{w(\text { initial Lignin })}\right] \times 100[\%]$

Gasous products[wt\%]

$$
=100-(\text { EtOAc soluble products }+ \text { THF soluble products }- \text { char })
$$

product selectivity $[\%]=\left[\frac{w(\text { product })}{w(\text { total products })}\right] \times 100[\%]$
Table 18 Characteristics of

\begin{tabular}{|c|c|c|c|c|}
\hline Catalyst & $\mathrm{SiO}_{2} / \mathrm{Al}_{2} \mathrm{O}_{3}$ ratio & Pore dimensions $\left[\mathrm{A}^{\circ}\right]$ & $\begin{array}{l}\text { Average pore size } \\
\text { [nm] }\end{array}$ & Description \\
\hline ZSM-5 & $23,50,280$ & $5.1 \times 5.5,5.3 \times 5.6$ & $0.52-0.55$ & $\begin{array}{l}\text { 10-membered } \\
\text { rings (MFI) } \\
\text { orthorhom- } \\
\text { bic }\end{array}$ \\
\hline Beta & $25,38,360$ & $6.6 \times 6.7$ & $0.61-0.62$ & $\begin{array}{l}\text { 10, } 12-\text { mem- } \\
\text { bered rings } \\
\text { (BEA) } \\
\text { tetragonal }\end{array}$ \\
\hline
\end{tabular}
zeolites tested (Mihalcik et al. 2011) 
Table 19 Quantitative and statistical analysis of the wt $\%$ of pyrolytic products observed following catalytic pyrolysis of component and lignocellulosic feedstocks over H-ZSM-5 (23); relative values of NCG's, solid residue and total calculated condensable vapors using H-ZSM-5 series (Mihalcik et al. 2011)

\begin{tabular}{|c|c|c|c|c|c|c|}
\hline & Lignin & ETEK Lignin $^{a}$ & Oak & Corn cob & Corn stover & Switchgrass \\
\hline 42 & 0.0091 & 1.72 & 2.31 & 3.07 & 1.72 & 2.17 \\
\hline 43 & 0.022 & 0.011 & 0.016 & 0.013 & 0.014 & 0.020 \\
\hline 44 & 0.018 & 0.010 & 0.023 & 0.021 & 0.017 & 0.010 \\
\hline 45 & 0.010 & 0.12 & 0.93 & 0.31 & 0.013 & 0.020 \\
\hline 46 & 0.019 & 0.019 & 0.48 & 0.0094 & 0.025 & 0.019 \\
\hline Guaiacol (23) & 0.12 & 0.15 & 0.099 & 0.10 & 0.084 & 0.093 \\
\hline 47 & 0.22 & 0.018 & 0.12 & 0.048 & 0.037 & 0.016 \\
\hline Phenol (12) & 0.15 & 0.22 & 0.16 & 0.19 & 0.17 & 0.11 \\
\hline Benzene (13) & 0.139 & 2.96 & 2.93 & 3.12 & 3.17 & 1.86 \\
\hline Toluene (29) & 2.68 & 2.24 & 2.28 & 2.23 & 2.17 & 3.36 \\
\hline Ethyl benzene (30) & 0.21 & 0.30 & 0.37 & 0.41 & 0.37 & 2.10 \\
\hline p-xylene (48) & 2.46 & 3.17 & 4.12 & 3.49 & 3.65 & 2.56 \\
\hline o-xylene (49) & 0.40 & 0.63 & 0.74 & 0.77 & 0.77 & 0.55 \\
\hline Naphthalene (35) & 0.75 & 1.33 & 1.37 & 1.33 & 1.33 & 0.89 \\
\hline Methyl Naphthalene (37) & 0.70 & 1.19 & 1.28 & 1.16 & 1.12 & 0.81 \\
\hline \multicolumn{7}{|l|}{$H-Z S M-5(23)$} \\
\hline NCG's ${ }^{b}$ & 15.5 & 26.9 & 26.5 & 28.1 & 40.4 & 28.9 \\
\hline Solid residue & 19.8 & 11.9 & 13.9 & 23.4 & 28.2 & 19.4 \\
\hline Condensables & 64.7 & 61.2 & 59.6 & 48.5 & 31.4 & 51.7 \\
\hline \multicolumn{7}{|l|}{$H-Z S M-5(50)$} \\
\hline NCG's ${ }^{b}$ & 20.9 & 23.9 & 34.9 & 33.3 & 31.7 & 31.1 \\
\hline Solid residue & 11.4 & 29.0 & 20.5 & 15.3 & 27.7 & 15.9 \\
\hline Condensables & 67.7 & 47.1 & 44.6 & 51.4 & 40.6 & 53.0 \\
\hline \multicolumn{7}{|l|}{$H-Z S M-5(280)$} \\
\hline NCG's ${ }^{b}$ & 14.7 & 21.9 & 21.3 & 25.3 & 26.3 & 28.1 \\
\hline Solid residue & 33.2 & 10.7 & 8.9 & 14.0 & 22.8 & 22.5 \\
\hline Condensables & 52.1 & 67.4 & 69.8 & 60.7 & 50.9 & 49.4 \\
\hline
\end{tabular}

The experiment illustrates that by using $\mathrm{NaOH}$ as a solvent, a high lignin conversion could be achieved. This was backed up by the fact that in entry 6 , when no $\mathrm{NaOH}$ was present in the solvent, a comparatively lower lignin yield was achieved. Furthermore, when only water and $\mathrm{MeOH}$ were used as solvents, a lower lignin conversion was also obtained. The solubility of lignin was evidently improved by the addition of $\mathrm{NaOH}$. However, lignin is insoluble in water and very poorly soluble in $\mathrm{MeOH}$, making them unsuitable solvents (Singh und Ekhe 2015). Furthermore, exposure to $\mathrm{NaOH}$ caused less formation of char, which is an undesirable by-product. The ratio of water to $\mathrm{MeOH}$ of $30: 30 \mathrm{~mL}-1$ as well as of 45:15 mL-1 was most suitable for the depolymerization of monomers. With regard to the catalyst, the $\mathrm{Cu} / \mathrm{Mo}$-ZSM-5 catalyst performed particularly well, since both high lignin conversion rates and high monomer yields were achieved (Singh und Ekhe 2015). In all tests, it performed better in this respect than the Cu-ZSM-5 catalyst. In addition, the Cu/Mo-ZSM-5 catalyst was recycled and successfully used for three cycles without any significant difference in efficiency. In terms of both lignin conversion and monomer yield, the highest conversions were obtained with the HZSM-5. However, it was negative that no high product selectivity for a phenol was formed. Only higher amounts of emulsified phenols and hydro-deoxygenated products such as acyclic hydrocarbons and aromatics were obtained. The catalyst could be recovered and reused after the reaction (Singh und Ekhe 2015). However, the quality of the catalyst continued to decrease after each cycle was used. The catalyst could be used for a total of three cycles with loss of quality (Singh und Ekhe 2015). 
Table 20 Quantitative and statistical analysis of the wt\% of pyrolytic products (1-15) observed following catalytic pyrolysis of component and lignocellulosic feedstocks over H-Beta (Mihalcik et al. 2011)
Table 21 Total acidity and surface area characteristics of synthesized catalysts (Singh und Ekhe 2015)

\begin{tabular}{|c|c|c|c|c|c|c|}
\hline & Lignin & ETEK Lignin $^{a}$ & Oak & Corn cob & Corn stover & Switchgrass \\
\hline 42 & 0.017 & 1.7 & 0.0082 & 1.76 & 1.90 & 2.23 \\
\hline 43 & 0.018 & 0.016 & 0.025 & 0.016 & 0.013 & 0.23 \\
\hline 44 & 0.021 & 0.018 & 0.017 & 0.021 & 0.012 & 0.016 \\
\hline 45 & 0.00046 & 0.14 & 0.0088 & 0.12 & 0.016 & 0.11 \\
\hline 46 & 0.016 & 0.018 & 0.14 & 0.0093 & 0.018 & 0.021 \\
\hline Guaiacol (23) & 0.13 & 0.11 & 0.019 & 0.080 & 0.077 & 0.073 \\
\hline 47 & 0.063 & 0.023 & 0.014 & 0.010 & 0.016 & 0.016 \\
\hline Phenol (12) & 0.16 & 0.12 & 0.087 & 0.11 & 0.11 & 0.10 \\
\hline Benzene (13) & 1.33 & 1.48 & 1.44 & 1.51 & 1.43 & 0.96 \\
\hline Toluene (29) & 1.83 & 1.95 & 2.05 & 2.17 & 2.21 & 1.44 \\
\hline Ethyl benzene (30) & 0.17 & 0.20 & 0.20 & 0.25 & 0.26 & 0.66 \\
\hline p-xylene (48) & 0.96 & 0.97 & 1.10 & 1.09 & 1.21 & 0.78 \\
\hline o-xylene (49) & 0.39 & 0.38 & 0.43 & 0.43 & 0.47 & 0.33 \\
\hline Naphthalene (35) & 0.70 & 0.53 & 0.60 & 0.63 & 0.56 & 0.48 \\
\hline Methyl Naphthalene (37) & 0.43 & 0.30 & 0.35 & 0.39 & 0.37 & 0.15 \\
\hline \multicolumn{7}{|l|}{ H-Beta (25) } \\
\hline NCG's ${ }^{b}$ & 30.9 & 24.8 & 18.2 & 26.2 & 28.4 & 31.9 \\
\hline Solid residue & 5.4 & 22.8 & 42.9 & 23.1 & 29.5 & 20.9 \\
\hline Condensables & 63.7 & 52.8 & 38.9 & 50.7 & 42.1 & 47.2 \\
\hline \multicolumn{7}{|l|}{ H-Beta (38) } \\
\hline NCG's ${ }^{b}$ & 31.9 & 23.8 & 18.6 & 24.1 & 30.7 & 33.3 \\
\hline Solid residue & 11.6 & 12.4 & 44.6 & 24.7 & 40.1 & 34.3 \\
\hline Condensables & 56.5 & 63.8 & 36.8 & 51.2 & 29.2 & 32.4 \\
\hline \multicolumn{7}{|l|}{ H-Beta $(360)$} \\
\hline NCG's ${ }^{b}$ & 20.4 & 20.1 & 18.9 & 23.9 & 27.3 & 27.7 \\
\hline Solid residue & 7.2 & 12.8 & 11.6 & 18.4 & 18.5 & 27.4 \\
\hline Condensables & 72.4 & 67.1 & 69.5 & 57.7 & 54.2 & 44.9 \\
\hline
\end{tabular}

${ }^{a}$ ETEK-Lignin: 50/50 mixture of cellulose and lignin

${ }^{\mathrm{b}} \mathrm{NCG}$ : non-condensable gas

\begin{tabular}{llll}
\hline & HZSM-5 & Cu/ZSM-5 & Cu-Mo/ZSM-5 \\
\hline $\mathrm{E}_{0}(\mathrm{mV})$ & 115 & -8 & -81 \\
Total acid strength & $\mathrm{vs}$ & $\mathrm{w}$ & $\mathrm{w}$ \\
Total number of acid sites $\left(\mathrm{m}_{\mathrm{eq}} \mathrm{g}^{-1}\right)$ & 0.33 & 0.29 & 0.13 \\
Density of acid sites $\left(\mu_{\mathrm{eq}} \mathrm{m}^{-2}\right)$ & 0.94 & 0.93 & 0.46 \\
BET surface area $\left(\mathrm{m}^{2} \mathrm{~g}^{-1}\right)$ & 352.2 & 308.8 & 281.7 \\
Average pore volume $\left(\mathrm{cm}^{3} \mathrm{~g}^{-1}\right)$ & 0.20 & 0.21 & 0.19 \\
\hline
\end{tabular}

\section{Palladium catalyst}

\section{Tandem-catalyzed reductive depolymerization with metal triflate and $\mathrm{Pd} / \mathrm{C}$}

In the subsequent experiment, the catalytic performance in the degradation of ligneous biomass by $\mathrm{Pd} / \mathrm{C}$ catalysts in combination with various metal triflates was investigated. The results are shown in Table 23. Pd/C catalysts are mainly involved in the cleavage of $\alpha-\mathrm{O}-4,4-\mathrm{O}-5$ and $\beta-\beta$ bonds of the aromatic lignin framework (Huang et al. 2017b). Metal triflates are responsible in the splitting of ester and ether linkages as well as the $\beta-\mathrm{O}-4$ ether bonds (Huang et al. $2017 b)$. Therefore, in the degradation of lignin, optimizing $\mathrm{Pd} / \mathrm{C}$ catalysts using metal triflates is an excellent application, as they become active in the cleavage of different types of bonds. The combination enables the promotion of the reductive fractionation process. In order to perform 
Table 22 Yields of products under different reaction conditions (Singh und Ekhe 2015)

\begin{tabular}{|c|c|c|c|c|c|c|c|c|c|}
\hline Entry & $\begin{array}{l}\text { Water/MeOH } \\
\text { ratio }^{\mathrm{a}}(\mathrm{ml} \\
\left.\mathrm{ml}^{-1}\right)\end{array}$ & Catalyst & $\begin{array}{l}\mathrm{NaOH} \\
(\mathrm{mmol})\end{array}$ & $\begin{array}{l}\text { Lignin } \\
\text { conversion }^{\mathrm{b}} \\
{[\%]}\end{array}$ & $\begin{array}{l}\text { Total EtOAc } \\
\text { soluble prod- } \\
\text { ucts [wt } \% \text { ] }\end{array}$ & $\begin{array}{l}\text { Monomeric } \\
\text { products }^{\mathrm{c}} \\
{[\mathrm{wt} \%]}\end{array}$ & $\begin{array}{l}\text { Oligomeric } \\
\text { Products }^{\mathrm{d}} \\
{[\mathrm{wt} \%]}\end{array}$ & $\begin{array}{l}\text { Gaseous } \\
\text { Products } \\
\text { [wt } \%]\end{array}$ & Char [wt\%] \\
\hline 1 & $30 / 30$ & $\begin{array}{l}\mathrm{Cu} / \mathrm{Mo}- \\
\text { ZSM-5 }\end{array}$ & 1.7 & 95.7 & 60.3 & 19.9 & 40.4 & 35.4 & 0.23 \\
\hline 2 & $45 / 15$ & $\begin{array}{l}\mathrm{Cu} / \mathrm{Mo}- \\
\mathrm{ZSM}-5\end{array}$ & 1.7 & 96.6 & 62.4 & 20.6 & 41.8 & 34.2 & 0.29 \\
\hline 3 & $15 / 45$ & $\begin{array}{l}\mathrm{Cu} / \mathrm{Mo}- \\
\text { ZSM-5 }\end{array}$ & 1.7 & 91.7 & 53.7 & 16.9 & 36.8 & 38 & 0.27 \\
\hline 4 & $0 / 60$ & $\begin{array}{l}\mathrm{Cu} / \mathrm{Mo}- \\
\text { ZSM-5 }\end{array}$ & 1.7 & 89.0 & 51.5 & 5.8 & 45.7 & 37.5 & 7.4 \\
\hline 5 & $60 / 0$ & $\begin{array}{l}\mathrm{Cu} / \mathrm{Mo}- \\
\text { ZSM-5 }\end{array}$ & 1.7 & 82.4 & 36.5 & 8.2 & 28.3 & 45.9 & 8.7 \\
\hline 6 & $30 / 30$ & $\begin{array}{c}\mathrm{Cu} / \mathrm{Mo}- \\
\text { ZSM-5 }\end{array}$ & 0 & 71.1 & 47 & n.d & n.d & 24.1 & 20.87 \\
\hline 7 & $30 / 30$ & $\begin{array}{l}\mathrm{Cu} / \mathrm{Mo}- \\
\mathrm{ZSM}-5\end{array}$ & 5.2 & 96 & 50.9 & n.d & n.d & 45.1 & 0.47 \\
\hline 8 & $30 / 30$ & $\mathrm{Cu} /-\mathrm{ZSM}-5$ & 1.7 & 83.2 & 61.2 & 17.7 & 43.5 & 22 & 0.53 \\
\hline 9 & $30 / 30$ & HZSM-5 & 1.7 & 98.5 & 60.9 & 22.5 & 38.4 & 37.6 & 0.3 \\
\hline
\end{tabular}

${ }^{\mathrm{a}}$ Water/MeOH ratio

${ }^{\mathrm{b}}$ Lignin conversion is calculated by deducting the EtOAc insoluble products (i.e., residual lignin and char)

${ }^{\mathrm{c}}$ Monomeric products $=$ products quantified by GC analysis

${ }^{\mathrm{d} O}$ Oligomeric products $=$ EtOAc soluble products — products quantified by GC analysis

${ }^{\mathrm{e}} \mathrm{Gaseous}$ products are calculated by deduction. f n.d. (not determined)

Table 23 Influence of metal on the tandem-catalyzed reductive depolymerization of lignocellulosic biomass in $\mathrm{MeOH}$ at $180{ }^{\circ} \mathrm{C}$ (Huang et al. 2017)

\begin{tabular}{|c|c|c|c|c|c|c|c|}
\hline \multirow[t]{2}{*}{ Entry } & \multirow[t]{2}{*}{ Catalyst } & \multirow[t]{2}{*}{ Co-catalyst } & \multirow[t]{2}{*}{$\begin{array}{l}\text { Residue } \\
\text { mass }[\mathrm{mg}]^{\mathrm{a}}\end{array}$} & \multicolumn{2}{|c|}{$\begin{array}{l}\text { Lignin monomers } \\
\text { yield [wt } \%] \text { [mg] }\end{array}$} & \multirow[t]{2}{*}{$\begin{array}{l}\text { Methylated C5 } \\
\text { sugars [mg] }\end{array}$} & \multirow{2}{*}{$\begin{array}{l}\text { Tota } \\
\text { yield } \\
{[\%]}\end{array}$} \\
\hline & & & & $1 \mathrm{~h}$ & $2 \mathrm{~h}$ & & \\
\hline 1 & $5 \mathrm{wt} \% \mathrm{Pd} / \mathrm{C}$ & None & 1790 & 10 & $14(64)$ & 6 & 93 \\
\hline 2 & $5 \mathrm{wt} \% \mathrm{Pd} / \mathrm{C}$ & $\mathrm{Ni}$ (II)-triflate & 1340 & 32 & 37 (176) & 194 & 86 \\
\hline 3 & $5 \mathrm{wt} \% \mathrm{Pd} / \mathrm{C}$ & $\mathrm{Cu}(\mathrm{II})$-triflate & 1360 & 33 & $34(163)$ & 162 & 84 \\
\hline 4 & $5 \mathrm{wt} \% \mathrm{Pd} / \mathrm{C}$ & $\mathrm{Al}(\mathrm{III})$-triflate & 1190 & 42 & 45 (212) & 352 & 88 \\
\hline 5 & $5 \mathrm{wt} \% \mathrm{Pd} / \mathrm{C}$ & $\mathrm{Yb}(\mathrm{III})$-triflate & 1360 & 39 & $43(203)$ & 205 & 88 \\
\hline 6 & $5 \mathrm{wt} \% \mathrm{Pd} / \mathrm{C}$ & Sc(III)-triflate & 1250 & 37 & 39 (187) & 259 & 85 \\
\hline 7 & $5 \mathrm{wt} \% \mathrm{Pd} / \mathrm{C}$ & $\mathrm{La}(\mathrm{III})$-triflate & 1390 & 32 & $36(171)$ & 190 & 88 \\
\hline 8 & $5 \mathrm{wt} \% \mathrm{Pd} / \mathrm{C}$ & Hf(IV)-triflate & 1110 & 40 & $42(200)$ & 345 & 83 \\
\hline 9 & $5 \mathrm{wt} \% \mathrm{Pd} / \mathrm{C}$ & $\mathrm{ZnCl} 2$ & 1690 & 14 & $22(104)$ & 31 & 91 \\
\hline 10 & $5 \mathrm{wt} \% \mathrm{Pd} / \mathrm{C}$ & $\mathrm{AlCl}$ & 1540 & 20 & $28(134)$ & 61 & 87 \\
\hline 11 & $5 \mathrm{wt} \% \mathrm{Pd} / \mathrm{C}$ & $\mathrm{Yb}(\mathrm{III})$-triflate ${ }^{\mathrm{b}}$ & 1470 & 9 & $17(82)$ & 106 & 83 \\
\hline
\end{tabular}

${ }^{a}$ Mass of the residue excluding $\mathrm{Pd} / \mathrm{C}$ catalyst and moisture

b30 bar $\mathrm{N}_{2}$ was added instead of $\mathrm{H}_{2}$ such a procedure, $2000 \mathrm{mg}$ of extracted birch wood sawdust $(125-300 \mu \mathrm{m})$ and $200 \mathrm{mg}$ of $5 \mathrm{wt} \%$ of the $\mathrm{Pd} / \mathrm{C}$ catalyst as well as $0.0322 \mathrm{mmol}$ of each of the cocatalysts were loaded into a reactor together with $40 \mathrm{ml}$ of the $\mathrm{MeOH}$ solvent (Huang et al. 2017b). All these components were mixed at 30 bar hydrogen at a stirring speed of $500 \mathrm{rpm}$ for one and two hours, respectively. In addition, a comparison was made of the influence of the replacement of nitrogen with hydrogen on the reaction. For this purpose, the experiment with the co-catalysator $\mathrm{Yb}(\mathrm{III})$ triflate was carried out under the same conditions with nitrogen and hydrogen. To analyze the obtained liquid products, a Shimadzu 2000 GC-MS system equipped with a RTX-1701 column, a flame ionization detector (FID) as well as mass spectrometer (MS) detector was applied (Huang et al. 2017b). To determine the lignin yield of the monomers, the following equation was used: 
Yield of monomers [wt $\%$ ]

$$
=\frac{\text { weight of monomers }}{\text { weight of starting feedstock } \times \text { lignin weight percentage in feedstock }} \times 100 \%
$$

To quantify the sugars, the obtained hydrolysates were first diluted 5 times with a solution containing the concentration of the internal standard fucose. Subsequently, the sugars were determined by comparison with certain sugar samples by injecting relative response factors (Huang et al. 2017b).

The experiment shows that by using different triflates as co-catalysts, the yields of $\mathrm{C}_{9}$ lignin monomers were increased. In addition, it was observed that by using triand tetravalent metal triflates such as $\mathrm{Al}, \mathrm{Sc}, \mathrm{La}$ and $\mathrm{Hf}$, a higher recovery of lignin monomers was achieved than by using divalent triflates such as $\mathrm{Ni}$ and $\mathrm{Cu}$ (Huang et al. 2017b). This may possibly be attributed to the fact that the cation charge increases with higher Lewis acidity. This is supported by the fact that by reference to pyridine IR, it was discovered that the Lewis acidity in ionic liquids is higher for trivalent and tetravalent metal triflates (Huang et al. 2017b). The best results with the highest yield were obtained in the experiment with $\mathrm{Al}(\mathrm{III})$ triflate. Likewise, high yielding results were obtained with $\mathrm{Hf}(\mathrm{IV})$ triflate and $\mathrm{Yb}(\mathrm{III})$ triflate. However, $\mathrm{Yb}$ is a rather rare metal; hence, the use of $\mathrm{Hf}$ and $\mathrm{Al}$ triflates is more profitable (Huang et al. $2017 b$ ). Considering the recovery of the methylated $C_{5}$ sugars, a higher result was also obtained with $\mathrm{Al}(\mathrm{III})$ and $\mathrm{Hf}(\mathrm{IV})$ triflate. This indicates that a higher degree of hemicellulose removal was achieved. Since lignin in lignocellulose is bound to hemicellulose, it can be concluded that a higher degree of lignin monomer extraction was obtained. When the reaction time was increased from 1 to $2 \mathrm{~h}$, only a slight improvement in the monomer yield was produced. Among other things, this could be due to the fact that the predominant $\beta$-O-4 ether bonds are cleaved initially, which happens quite rapidly. This type of bond is the main linkage in lignin that has to be cleaved to gain monomers. Subsequently, the remaining bonds are cleaved, which proceeds considerably slower (Huang et al. 2017b). The experiment also demonstrated that the use of the co-catalysts $\mathrm{AlCl}_{3}$ and $\mathrm{ZnCl}_{2}$ is less advantageous for the conversion of lignocellulose. Both catalysts are conventional Lewis acids (Huang et al. 2017b). Etherification and hydrogenolysis reactions produce water, which can lead to a hydrolysis reaction, reducing the efficiency of these Lewis acids (Huang et al. 2017b). Finally, it could not be evidenced that the use of hydrogen is much more beneficial for the degeneration of lignin than nitrogen, which also demonstrates that transfer hydrogenation reactors are inefficient (Huang et al. 2017b).

\section{Lignin hydrogenolysis: Comparison of $\mathrm{Ru} / \mathrm{C}$ and $\mathrm{Pd} / \mathrm{C}$ catalyst}

The efficiency of the $\mathrm{Pd} / \mathrm{C}$ catalyst was tested by comparing its performance with that of a $\mathrm{Ru} / \mathrm{C}$ catalyst under identical reaction conditions. The results are summarized in Table 24. $2 \mathrm{~g}$ extracted birch sawdust consisting of 19.5 wt $\%$ Klason lignin and $41 / 21 \mathrm{wt} \% \mathrm{C}_{6} / \mathrm{C}_{5}$ sugars along with $0.2 \mathrm{~g}$ each of the respective catalyst were heated together with $40 \mathrm{~mL}$ of the solvent $\mathrm{MeOH}$ for $3 \mathrm{~h}$ at $523 \mathrm{~K}$ at $3 \mathrm{MPa}$ hydrogen in a reactor (van den Bosch et al. 2015). Both catalysts are platinum metals. A fairly similar yield of lignin monomers of almost $50 \%$ was obtained by using both catalysts. However, a gas chromatogram showed that the product selectivity differs. The $\mathrm{Ru} / \mathrm{C}$ catalyst tends to generate para-propyl phenolics. Thus, $75 \%$ of dihydroeugenol (also called 4-propylguaiacol) (1) and propylsyringol (2) were formed. The Pd/C catalyst, on the other hand, tended to form para-propanol phenolics. A majority of 91\% of 4-(3-hydroxypropyl)-2-methoxyphenol (7) and

Table 24 Comparison of the results after lignin hydrogenolysis on birch wood with a Ru/C and Pd/C catalyst (van den Bosch et al. 2015)

\begin{tabular}{lll}
\hline & $\mathrm{Ru} / \mathrm{C}$ & $\mathrm{Pd} / \mathrm{C}$ \\
\hline Lignin fraction & & \\
Delignification [wt\%] & 85 & 90 \\
Monomer yield [C \%] & 48 & 49 \\
$\mathrm{PG}+\mathrm{PS}$ selectivity [\%] & 75 & 4 \\
PohG + PohS selectivity [\%] & 19 & 91 \\
Dimer yield [C \%] & 13 & 15 \\
OH's in lignin oil [mmol g ${ }^{-1}$ ] & 7.9 & 9.7 \\
OH's per monomer unit & 1.5 & 1.9 \\
Carbohydrate fraction & & \\
C5 retention [C \%] & 69 & 81 \\
C6 retention [C \%] & 93 & 94 \\
Total sugar retention [C \%] & 85 & 89 \\
Composition of the gas phase (vol\%) & & \\
$\mathrm{H}_{2}$ & 92.7 & 94.2 \\
$\mathrm{~N}_{2}$ & 3.4 & 4.1 \\
CH & & \\
CO & $1.1(0.08)$ & $0.2(0.01)$ \\
Maximum loss of MeOH into carbona- ceous gases [mol\%] & 0.21 & $0.9(0.05)$ \\
\hline
\end{tabular}


4-(3-hydroxypropyl)-2-6-dimethoxyphenol was observed. Furthermore, a remarkably similar delignification rate of around $90 \%$ could be achieved with both catalysts (van den Bosch et al. 2015). In the yield of the di- and oligomers, only a slight difference in selectivity was observed. However, somewhat larger di- and oligomers were obtained by the $\mathrm{Pd} / \mathrm{C}$ catalyst. This can probably be attributed to the higher $\mathrm{OH}$ content of the catalyst (van den Bosch et al. 2015). The experiment has demonstrated that a high yield of different phenolic monomers can be obtained from birch wood using $\mathrm{MeOH}$ as solvent and a hydrogenic atmosphere. This is caused by a catalyst that induces a redox reaction. Besides phenols, additional di- and oligomers and carbohydrate pulp are also obtained under these reaction conditions. Depending on which catalyst is chosen, it is possible to control the product selectivity. In the case of lignin conversion, the $\mathrm{Pd} / \mathrm{C}$ catalyst has proven to be particularly advantageous, as it allows more $\mathrm{OH}$ groups to be obtained (van den Bosch et al. 2015). The lignin oils obtained by the two catalysts were analyzed by 2D HSQC, 13C and 1 H NMR (van den Bosch et al. 2015). This allowed the components to be characterized and subsequently compared.

\section{Lignin hydrogenolysis: $\mathrm{Pd} / \mathrm{C}+\mathrm{CrCl}_{3}$}

The following experiment has the lignin conversion of the three different lignin species dealkaline lignin, sodium lignosulfonate and organosolv lignin caused by a catalytic hydrogenolysis. For this purpose, the catalyst $\mathrm{Pd} / \mathrm{C}$ and in combination with the co-catalyst $\mathrm{CrCl} 3$ were used. For this purpose, $0.5 \mathrm{~g}$ each of the $5 \mathrm{w} \% \mathrm{Pd} / \mathrm{C}$ catalyst was heated with $40 \mathrm{~mL}$ of $1 \mathrm{mmol} \mathrm{MeOH}$ in a reactor at $4 \mathrm{MPa}$ hydrogen for $5 \mathrm{~h}$ at $280{ }^{\circ} \mathrm{C}$ (Shu et al. 2016). The catalyst was then mixed with $1 \mathrm{mmol} \mathrm{MeOH}$. In the co-catalyst experiments, $0.1 \mathrm{hg} \mathrm{\textrm {CrCl } _ { 3 }}$ was also added. The results are summarized in Table 25. It can be seen that without the use of the catalyst, liquefaction could be induced in all three lignin species by the increased heat alone. For all three types, the liquefaction was around $60 \%$ (Shu et al. 2016). The product selectivity was also quite low compared to the other verses. The experiments in which the catalyst $\mathrm{Pd} / \mathrm{C}$ was added showed an increased lignification. However, the selectivity with respect to aliphatic alcohols, hydrocarbons, guaiacols and phenols was only slightly increased. However, the highest yields of oligomers were obtained. By supporting the $\mathrm{Pd} / \mathrm{C}$ catalyst with the co-catalyst $\mathrm{CrCl}_{3}$, a significant increase in the degree of lignification was achieved. This was around $80 \%$ for all three lignin types. The increased product yield was also remarkable, especially for the phenols. In order to determine the degree of lignin liquefaction as well as the obtained yield, the following equations were used (Shu et al. 2016):

$$
\begin{aligned}
& D_{L}(\%)=\left(W_{F}-W_{R}\right) / W_{F} \times 100 \% \\
& Y_{A}(\%)=W_{A} / W_{F} \times 100 \% \\
& Y_{H}(\%)=W_{H} / W_{F} \times 100 \% \\
& Y_{G}(\%)=W_{G}=W_{F} \times 100 \% \\
& Y_{P}(\%)=W_{P}=W_{F} \times 100 \% \\
& Y_{O t h e r}(\%)=Y_{V}-Y_{A}-Y_{H}-Y_{G}-Y_{P} \\
& Y_{O}=\left(W_{F}-W_{R}-W_{V}\right) / W_{F} \times 100 \%
\end{aligned}
$$

\begin{tabular}{|c|c|c|c|c|c|c|c|c|}
\hline \multirow[t]{2}{*}{ Lignin } & \multirow[t]{2}{*}{ Catalyst } & \multirow{2}{*}{$\begin{array}{l}\text { Degree of lignin } \\
\text { liquefaction [\%] }\end{array}$} & \multicolumn{6}{|l|}{ Weight yield [\%] } \\
\hline & & & Aliphatic alcohol & Hydrocarbon & Guaiacols & Phenols & $\begin{array}{l}\text { Other volatile } \\
\text { products }\end{array}$ & Oligomer \\
\hline \multirow[t]{3}{*}{ Dealkaline lignin } & - & $64.0 \pm 1.42$ & $0.8 \pm 0.01$ & $0.4 \pm 0.02$ & $1.2 \pm 0.08$ & $2.0 \pm 0.02$ & $5.2 \pm 0.17$ & $54.4 \pm 1.17$ \\
\hline & $\mathrm{Pd} / \mathrm{C}$ & $71.2 \pm 1.18$ & $1.2 \pm 0.05$ & $0.5 \pm 0.05$ & $1.4 \pm 0.04$ & $2.2 \pm 0.08$ & $7.6 \pm 0.24$ & $58.3 \pm 1.43$ \\
\hline & $\mathrm{Pd} / \mathrm{C}+\mathrm{CrCl}_{3}$ & $82.6 \pm 1.48$ & $2.7 \pm 0.11$ & $1.8 \pm 0.08$ & $1.8 \pm 0.04$ & $13.8 \pm 0.43$ & $16.7 \pm 0.50$ & $45.8 \pm 1.94$ \\
\hline \multirow{3}{*}{$\begin{array}{l}\text { Sodium lignosul- } \\
\text { fonate }\end{array}$} & - & $60.0 \pm 0.99$ & $1.7 \pm 0.04$ & $0.8 \pm 0.01$ & $0.5 \pm 0.02$ & $3.0 \pm 0.11$ & $7.0 \pm 0.23$ & $47.0 \pm 1.21$ \\
\hline & $\mathrm{Pd} / \mathrm{C}$ & $67.6 \pm 1.52$ & $1.9 \pm 0.07$ & $0.9 \pm 0.03$ & $0.6 \pm 0.04$ & $3.6 \pm 0.10$ & $8.4 \pm 0.31$ & $52.2 \pm 1.90$ \\
\hline & $\mathrm{Pd} / \mathrm{C}+\mathrm{CrCl}_{3}$ & $83.2 \pm 1.55$ & $5.2 \pm 0.20$ & $2.1 \pm 0.07$ & $1.7 \pm 0.07$ & $6.1 \pm 0.27$ & $18.2 \pm 0.75$ & $49.9 \pm 1.64$ \\
\hline \multirow[t]{3}{*}{ Organosolv lignin } & - & $57.0 \pm 1.52$ & $0.7 \pm 0.02$ & $0.3 \pm 0.06$ & $1.8 \pm 0.07$ & $2.6 \pm 0.09$ & $7.5 \pm 0.38$ & $44.1 \pm 1.94$ \\
\hline & $\mathrm{Pd} / \mathrm{C}$ & $63.8 \pm 2.07$ & $1.0 \pm 0.03$ & $0.4 \pm 0.10$ & $2.0 \pm 0.09$ & $3.2 \pm 0.09$ & $9.2 \pm 0.29$ & $48.0 \pm 2.21$ \\
\hline & $\mathrm{Pd} / \mathrm{C}+\mathrm{CrCl}_{3}$ & $78.2 \pm 1.79$ & $3.4 \pm 0.07$ & $1.7 \pm 0.12$ & $2.6 \pm 0.11$ & $16.5 \pm 0.87$ & $23.2 \pm 1.07$ & $30.8 \pm 1.89$ \\
\hline
\end{tabular}

\section{Metal chloride cooperated with $\mathrm{Pd} / \mathrm{C}$ and effect of Lewis acid}

The following experiment demonstrates the effect of Lewis acidity on the degree of lignin liquefaction and on

Table 25 Effect of catalysts on lignin hydrogenolysis and product distribution (Shu et al. 2016) 
the resulting volatile products. For this purpose, $0.5 \mathrm{~g}$ of alkali lignin, $0.1 \mathrm{~g}$ of $5 \mathrm{wt} \% \mathrm{Pd} / \mathrm{C}$ catalyst, $0.5 \mathrm{mmol}$ of the respective Lewis acid that was used as well as $40 \mathrm{~mL}$ of $\mathrm{MeOH}$ were heated in a $100-\mathrm{ml}$ autoclave at $260{ }^{\circ} \mathrm{C}$ for $5 \mathrm{~h}$. Beforehand, the autoclave was purged 3 times with hydrogen. After $5 \mathrm{~h}$, the reaction was terminated by cooling the reactor to room temperature (Shu et al. 2015). The resulting product mixture was subsequently filtered. The solid fraction was rinsed 3 times with $\mathrm{MeOH}$ and thereafter dried at $80^{\circ} \mathrm{C}$. The remaining filtrate was collected and diluted with $\mathrm{MeOH}$ to a certain volume. Afterward, the quantitative and qualitative analysis was carried out using a gas chromatograph equipped with a thermal conductivity detector (TCD) and a flame ionization detector (Shu et al. 2015). Analysis of the collected gas has shown that the gaseous products were only about $1 \mathrm{wt} \%$ of the feed lignin, and therefore its yield was neglected here (Shu et al. 2015). For the phenolic compounds, helium was used as the carrier material, and for the volatile products, acetophenone was used as the internal standard chemical (Shu et al. 2015). The following equations were used to calculate the obtained yields and the degree of lignin liquefaction:
$\mathrm{Pd} / \mathrm{C}$ is added. This resulted in a higher degree of lignification, but the product yield was not particularly affected. An increase in phenol yield was achieved by adding $\mathrm{Pd} / \mathrm{C}$ catalyst containing MCLx to the lignin molecules (Shu et al. 2015). This also significantly increased the degree of lignification. It should be noted that if an acidic catalyst is used, the ether bonds in the lignin, such as $\beta-\mathrm{O}-4$ or $4-\mathrm{O}-5$, are easier to break, which further improves the liquefaction of lignin. In addition, atomic $\mathrm{H}$ on the surface of the Pd reduces the active energy of the ether bonds (Shu et al. 2015). Cl has a high electronegativity and is also an excellent hydrogen bond acceptor. Experiments show that by using the ionic liquid $\mathrm{Cl}$, the $\mathrm{C}-\mathrm{O}$ bonds in cellulose could be broken more efficiently than by using other solvents. These $\mathrm{C}-\mathrm{O}$ bonds are also present in lignin molecules, which is why the use of MClx is beneficial in the conversion of lignin molecules. It can be assumed that $\mathrm{Cl}$ in Lewis acid acts as a hydrogen bond acceptor for lignin as well as a polarization reagent for $\mathrm{C}-\mathrm{O}$ bonds in these molecules (Shu et al. 2015). All experiments carried out showed that by using a Pd/C catalyst, in which MCLx was cooperated, an increase in the degree of lignin liquefaction as well as a higher yield of phenolic products

Degree of lignin liquefacation $[\%]=\frac{\text { weight of feed lignin }- \text { weight of residual solid }}{\text { weight of feed lignin }} \times 100 \%$

Yield of phenolic monomer $[\%]=\frac{\text { weight of phenolic monomer }}{\text { weight of feed lignin }} \times 100 \%$

Yield of phenols $[\%]=\frac{\text { weight of phenols }}{\text { weight of feed lignin }} \times 100 \%$

Yield of guaiacols $[\%]=\frac{\text { weight of guaiacols }}{\text { weight of feed lignin }} \times 100 \%$

Yield of other phenolic monomer $[\%]=$ yield of phenolic monomer - yield of phenols - yield guaiacols

could be achieved. Furthermore, it was found in the experiment that increasing valence of the metal cation increased the lignin liquefaction. This can probably be attributed to the fact that the Lewis acid strength caused the effect by the metal cation (Shu et al. 2015). This is because the lignin hydrogenation could be promoted by the metal cations with a higher valence forming acidic centers and thus improving

Yield of nonvolatile products $[\%]=\frac{\text { weight of feed lignin }- \text { weight of residual solid }- \text { weight of voltaile products }}{\text { weight of feed lignin }} \times 1604 \%$

The findings of the experiment are shown in Table 26. The reaction conditions result in a lignification of up to $49.8 \%$ even without the use of a catalyst. This value is the lowest compared to the rest of the experiments where a catalyst was present. This also applies to the yield of phenolic monomers, which was merely $5.6 \%$. In the second experiment, the improvement of the catalyst becomes evident as the catalyst the acid effect of the catalyst. Among other things, therefore, the lignin depolymerization was higher when $\mathrm{AlCl}_{3}$ was used than, for example, when $\mathrm{MgCl}_{2}$ was used. It should also be noted that the higher proportion of $\mathrm{Cl}$ in $\mathrm{AlCl}_{3}$ also increases the depolymerization of the lignin (Shu et al. 2015). In particular, the use of $\mathrm{LiCl}$ resulted in a higher phenol yield compared to bivalent metal chlorides such as $\mathrm{BaCl}_{2}$ or $\mathrm{NiCl}_{2}$. 
Table 26 Effect of Lewis acid on lignin depolymerization and product distribution (Shu et al. 2015)

\begin{tabular}{|c|c|c|c|c|c|c|c|c|c|}
\hline \multirow[t]{2}{*}{ Entry } & \multirow[t]{2}{*}{ Lewis acid } & \multirow[t]{2}{*}{ Catalyst } & \multirow{2}{*}{$\begin{array}{l}\text { Degree of lignin } \\
\text { liquefaction [\%] }\end{array}$} & \multicolumn{4}{|c|}{ Yield of the phenolic monomer [\%] } & \multirow{2}{*}{$\begin{array}{l}\text { Yield of other volatile } \\
\text { chemicals exclude phenolic } \\
\text { monomer }[\%]\end{array}$} & \multirow{2}{*}{$\begin{array}{l}\text { Yield of non- } \\
\text { volatile products } \\
{[\%]}\end{array}$} \\
\hline & & & & $\begin{array}{l}\text { yield of } \\
\text { phenols }\end{array}$ & $\begin{array}{l}\text { yield of } \\
\text { guai- } \\
\text { acols }\end{array}$ & $\begin{array}{l}\text { yield of other } \\
\text { phenolic mono- } \\
\text { mer }\end{array}$ & Total & & \\
\hline 1 & $-^{\mathrm{a}}$ & - & 49.8 & 0.3 & 3.9 & 1.4 & 5.6 & 1.4 & 42.8 \\
\hline 2 & $-{ }^{\mathrm{b}}$ & $\mathrm{Pd} / \mathrm{C}$ & 58.5 & 1.5 & 2.6 & 2.7 & 6.8 & 1.0 & 50.7 \\
\hline 3 & $\mathrm{LiCl}$ & $\mathrm{Pd} / \mathrm{C}$ & 72.0 & 2.4 & 3.3 & 5.4 & 11.1 & 0.6 & 60.3 \\
\hline 4 & $\mathrm{NaCl}$ & $\mathrm{Pd} / \mathrm{C}$ & 63.5 & 2.6 & 4.7 & 0.9 & 8.2 & 0.8 & 54.5 \\
\hline 5 & $\mathrm{KCl}$ & $\mathrm{Pd} / \mathrm{C}$ & 63.4 & 1.7 & 4.9 & 2.2 & 8.8 & 0.7 & 53.9 \\
\hline 6 & $\mathrm{BaCl}_{2}$ & $\mathrm{Pd} / \mathrm{C}$ & 64.0 & 0.8 & 4.7 & 1.3 & 6.8 & 0.2 & 57.0 \\
\hline 7 & $\mathrm{CuCl}_{2}$ & $\mathrm{Pd} / \mathrm{C}$ & 66.0 & 2.1 & 3.5 & 3.6 & 9.2 & 0.5 & 56.3 \\
\hline 8 & $\mathrm{FeCl}_{2}$ & $\mathrm{Pd} / \mathrm{C}$ & 72.0 & 4.1 & 2.3 & 2.1 & 8.5 & 0.3 & 63.2 \\
\hline 9 & $\mathrm{NiCl}_{2}$ & $\mathrm{Pd} / \mathrm{C}$ & 74.0 & 0.7 & 5.8 & 3.8 & 10.3 & 0.2 & 63.5 \\
\hline 10 & $\mathrm{ZnCl}_{2}$ & $\mathrm{Pd} / \mathrm{C}$ & 76.0 & 2.2 & 6.9 & 3.9 & 13.0 & 3.4 & 59.6 \\
\hline 11 & $\mathrm{MgCl}_{2}$ & $\mathrm{Pd} / \mathrm{C}$ & 82.7 & 4.1 & 3.1 & 12.4 & 19.6 & 3.4 & 59.7 \\
\hline 12 & $\mathrm{FeCl}_{3}$ & $\mathrm{Pd} / \mathrm{C}$ & 84.0 & 1.0 & 5.1 & 0.6 & 6.7 & 0.4 & 76.9 \\
\hline 13 & $\mathrm{AlCl}_{3}$ & $\mathrm{Pd} / \mathrm{C}$ & 91.4 & 5.3 & 0.9 & 19.8 & 26.0 & 3.2 & 62.2 \\
\hline 14 & $\mathrm{CrCl}_{3}$ & $\mathrm{Pd} / \mathrm{C}$ & 80.7 & 7.3 & 2.8 & 18.4 & 28.5 & 4.0 & 48.2 \\
\hline 15 & $\mathrm{Cr}_{3} \mathrm{C}_{2}$ & $\mathrm{Pd} / \mathrm{C}$ & 78.8 & 0.2 & 3.6 & 4.1 & 7.9 & 2.2 & 68.7 \\
\hline 16 & $\mathrm{Cr}\left(\mathrm{NO}_{3}\right)_{3}$ & $\mathrm{Pd} / \mathrm{C}$ & 89.7 & 3.8 & 5.2 & 7.6 & 16.6 & 1.3 & 71.8 \\
\hline 17 & $\mathrm{H}_{2} \mathrm{SO}_{4}$ & $\mathrm{Pd} / \mathrm{C}$ & 88.6 & 0.7 & 6.4 & 3.6 & 10.7 & 0.7 & 77.2 \\
\hline 18 & $\mathrm{HCl}$ & $\mathrm{Pd} / \mathrm{C}$ & 90.8 & 0.9 & 5.8 & 4.5 & 11.2 & 0.9 & 78.7 \\
\hline 19 & $\mathrm{CrCl}_{3}{ }^{\mathrm{c}}$ & - & 67.9 & 7.3 & 2.5 & 14.2 & 24.0 & 3.2 & 40.7 \\
\hline
\end{tabular}

${ }^{\mathrm{a}}$ Without both $\mathrm{Pd} / \mathrm{C}$ and Lewis acid

${ }^{\mathrm{b}}$ Without Lewis acid

${ }^{c}$ Without Pd/C

$\mathrm{Li}^{+}$molecules have the particular advantage that they have a comparatively similar radius to $\mathrm{H}^{+}$atoms (Shu et al. 2015). Therefore, $\mathrm{LiCl}$ catalysis is quite similar to $\mathrm{HCl}$ catalysis. The main products obtained in the experiments were guaiacol and its derivatives. This is due to the fact that the lignin used consisted largely of guaiacyl units (Shu et al. 2015). However, due to the presence of $\mathrm{CrCl}_{3}$ in the $\mathrm{Pd} / \mathrm{C}$, mainly phenols were obtained as products. This is due to the fact that $\mathrm{CrCl}_{3}$ operates as a Lewis acid as well as a coordinated catalyst for C-O bonds in lignin (Shu et al. 2015). The experiment has shown that by replacing the $\mathrm{Cl}$ with a carbon ion or with $\mathrm{NO}_{3}$, a severe decrease in the phenolic products yielded was caused. The synergistic effect between $\mathrm{Cl}$ and $\mathrm{Cr}^{3+}$ was largely responsible for the increased phenolic yield. In addition to the metal chlorides, the influence of the proton acids $\mathrm{H}_{2} \mathrm{SO}_{4}$ and $\mathrm{HCl}$ was also observed. The results show that only a small amount of phenols was converted. Moreover, in the presence of $\mathrm{HCl}$, a better catalytic activity was obtained than with $\mathrm{H}_{2} \mathrm{SO}_{4}$. This again proved that the $\mathrm{Cl}$ molecules have a strong effect on the depolymerization. In conclusion, the use of the $\mathrm{Pd} / \mathrm{C}$ catalyst in the presence of metal chlorides increased the yield of phenolic products (Shu et al. 2015). In addition, a higher valence of the metal chloride and a stronger Lewis acidity also had a positive effect (Shu et al. 2015).

\section{Conclusion}

The various experiments in which different catalyst types were used have highlighted the fact that lignin conversion and product selectivity can be significantly influenced by the choice of the catalyst type. Different catalysts promote the formation of different products. Furthermore, it was demonstrated that factors such as temperature, solvent, Lewis acid, lignin type and use of co-catalysts can significantly improve the efficiency of the catalyst, though the influence of, i.e., the solvent cannot be generalized. For example, using Ni/C polar protic solvents seem to be beneficial to the overall yield but water as solvent seems to be problematic. If RANEY nickel is used, unpolar solvents seem to have a very positive effect on the depolymerization, resulting in overall yields up to $100 \%$. Generally, the reaction type has to be considered. For example, zeolitic catalysts have proven to be suitable for the depolymerization of lignin by pyrolysis, whereas metal catalysts such as nickel-based catalysts are well-established for 
hydrogenolysis processes. Nickel catalysts are also quite efficient in the conversion of lignin to phenols. They also have the advantage of having mild reaction conditions. Another benefit of these catalysts is that they are fairly inexpensive. Pd-based catalysts have also been successfully used in the depolymerization of lignin. However, palladium is a rare metal, which is also rather expensive. Nickel, on the other hand, is an earth abundant metal. Zeolite catalysts are also less expensive than Pd catalysts and can also be used efficiently in pyrolysis processes. In addition, zeolites can be easily optimized for the process by desilication. Nonetheless, the economic aspects cannot be reduced to the costs of the corresponding catalysts. In addition, availability plays an important role. For example, established zeolites are indeed low priced, but if they have to be further processed or functionalized, they can become dull to a possible industrial user. But also the resulting product selectivity is of great importance. If many different substances have to be separated from each other, the process can become unprofitable. In our opinion, the most interesting techniques are those, where monoaromatic products can be isolated in a good yield/selectivity relation, which than can be used as basic chemicals in chemical industry replacing comparable compounds today still produced from fossil sources.

Acknowledgements We like to thank the ReAching program of the faculty MLS, Furtwangen University, for support.

Funding Open Access funding enabled and organized by Projekt DEAL.

Open Access This article is licensed under a Creative Commons Attribution 4.0 International License, which permits use, sharing, adaptation, distribution and reproduction in any medium or format, as long as you give appropriate credit to the original author(s) and the source, provide a link to the Creative Commons licence, and indicate if changes were made. The images or other third party material in this article are included in the article's Creative Commons licence, unless indicated otherwise in a credit line to the material. If material is not included in the article's Creative Commons licence and your intended use is not permitted by statutory regulation or exceeds the permitted use, you will need to obtain permission directly from the copyright holder. To view a copy of this licence, visit http://creativecommons.org/licenses/by/4.0/.

\section{References}

Adhikari S, Srinivasan V, Fasina O (2014) Catalytic pyrolysis of raw and thermally treated lignin using different acidic zeolites. Energy Fuels 28(7):4532-4538. https://doi.org/10.1021/ef500902x

Calvo-Flores FG, Dobado JA (2010) Lignin as renewable raw material. Chemsuschem 3(11):1227-1235. https://doi.org/10.1002/ cssc. 201000157

Font R, Esperanza M, García AN (2003) Toxic by-products from the combustion of Kraft lignin. Chemosphere 52(6):1047-1058. https://doi.org/10.1016/S0045-6535(03)00294-7
Forchheim D, Hornung U, Kempe P, Kruse A, Steinbach D (2012) Influence of RANEY Nickel on the Formation of Intermediates in the Degradation of Lignin. Int J Chem Eng 2012:1-8. https:// doi.org/10.1155/2012/589749

Geib SM, Filley TR, Hatcher PG, Hoover K, Carlson JE, JimenezGasco D, Mar M et al (2008) Lignin degradation in wood-feeding insects. Proc Natl Acad Sci United States Am 105(35):1293212937. https://doi.org/10.1073/pnas.0805257105

Goodell B (2003) Wood deterioration and preservation. Advances in our changing world. American Chemical Society; Symposium Wood Deterioration Mechanisms and Its Impact on Biotechnology and Wood Preservation; National meeting of the American Chemical Society. Washington, DC: American Chemical Society (ACS Symposium Series, 845).

Guigo N, Mija A, Vincent L, Sbirrazzuoli N (2010) Eco-friendly composite resins based on renewable biomass resources: Polyfurfuryl alcohol/lignin thermosets. Eur Polym J 46(5):10161023. https://doi.org/10.1016/j.eurpolymj.2010.02.010

Hoff TC, Gardner DW, Thilakaratne R, Proano-Aviles J, Brown RC, Tessonnier J-P (2017) Elucidating the effect of desilication on aluminum-rich ZSM-5 zeolite and its consequences on biomass catalytic fast pyrolysis. Appl Catal A 529:68-78. https://doi.org/ 10.1016/j.apcata.2016.10.009

Hosoya T, Kawamoto H, Saka S (2007) Pyrolysis behaviors of wood and its constituent polymers at gasification temperature. J Anal Appl Pyrol 78(2):328-336. https://doi.org/10.1016/j.jaap.2006. 08.008

Huang S, Mahmood N, Zhang Y, Tymchyshyn M, Yuan Z, Xu C (2017a) Reductive de-polymerization of kraft lignin with formic acid at low temperatures using inexpensive supported $\mathrm{Ni}$ based catalysts. Fuel 209:579-586. https://doi.org/10.1016/j. fuel.2017.08.031

Huang X, Morales Gonzalez OM, Zhu J, Korányi TI, Boot MD, Hensen EJM (2017b) Reductive fractionation of woody biomass into lignin monomers and cellulose by tandem metal triflate and Pd/C catalysis. Green Chem 19(1):175-187. https://doi.org/10. 1039/C6GC02962K

Kasakov S, Shi H, Camaioni DM, Zhao C, Baráth E, Jentys A, Lercher JA (2015) Reductive deconstruction of organosolv lignin catalyzed by zeolite supported nickel nanoparticles. Green Chem 17(11):5079-5090. https://doi.org/10.1039/C5GC0 2160J

Kawamoto H (2017) Lignin pyrolysis reactions. J Wood Sci 63(2):117132. https://doi.org/10.1007/s10086-016-1606-z

Klein I, Saha B, Abu-Omar MM (2015) Lignin depolymerization over $\mathrm{Ni} / \mathrm{C}$ catalyst in methanol, a continuation: effect of substrate and catalyst loading. Catal Sci Technol 5(6):3242-3245. https://doi. org/10.1039/C5CY00490J

Kleinert M, Barth T (2008) Phenols from Lignin. Chem Eng Technol 31(5):736-745. https://doi.org/10.1002/ceat.200800073

Li J, Li X, Zhou G, Wang W, Wang C, Komarneni S, Wang Y (2014) Catalytic fast pyrolysis of biomass with mesoporous ZSM-5 zeolites prepared by desilication with $\mathrm{NaOH}$ solutions. Appl Catal A 470:115-122. https://doi.org/10.1016/j.apcata.2013.10.040

Luo H, Klein IM, Jiang Y, Zhu H, Liu B, Kenttämaa HI, Abu-Omar MM (2016) Total utilization of miscanthus biomass, lignin and carbohydrates, using earth abundant nickel catalyst. ACS Sustain Chem Eng 4(4):2316-2322. https://doi.org/10.1021/acssuschem eng.5b01776

Mihalcik DJ, Mullen CA, Boateng AA (2011) Screening acidic zeolites for catalytic fast pyrolysis of biomass and its components. $\mathrm{J}$ Anal Appl Pyrol 92(1):224-232. https://doi.org/10.1016/j.jaap. 2011.06.001

Ouyang X, Huang X, Boot MD, Hensen EJM (2020) Efficient conversion of pine wood lignin to phenol. Chemsuschem 13(7):17051709. https://doi.org/10.1002/cssc.202000485 
Pandey MP, Kim CS (2011) Lignin depolymerization and conversion: a review of thermochemical methods. Chem Eng Technol 34(1):29-41. https://doi.org/10.1002/ceat.201000270

Pepper JM, Lee YW (1970) Lignin and related compounds. II Studies using ruthenium and Raney nickel as catalysts for lignin hydrogenolysis. Can J Chem 48(3):477-479

Saiz-Jimenez C, de Leeuw JW (1986) Lignin pyrolysis products: Their structures and their significance as biomarkers. Org Geochem 10(4-6):869-876. https://doi.org/10.1016/S0146-6380(86) 80024-9

Shu R, Long J, Yuan Z, Zhang Qi, Wang T, Wang C, Ma L (2015) Efficient and product-controlled depolymerization of lignin oriented by metal chloride cooperated with Pd/C. Biores Technol 179:84-90. https://doi.org/10.1016/j.biortech.2014.12.021

Shu R, Long J, Xu Y, Ma L, Zhang Qi, Wang T et al (2016) Investigation on the structural effect of lignin during the hydrogenolysis process. Biores Technol 200:14-22. https://doi.org/10.1016/j.biort ech.2015.09.112

Singh SK, Ekhe JD (2015) Cu-Mo doped zeolite ZSM-5 catalyzed conversion of lignin to alkyl phenols with high selectivity. Catal Sci Technol 5(4):2117-2124. https://doi.org/10.1039/C4CY01700E

Song Qi, Wang F, Cai J, Wang Y, Zhang J, Yu W, Xu J (2013) Lignin depolymerization (LDP) in alcohol over nickel-based catalysts via a fragmentation-hydrogenolysis process. Energy Environ Sci 6(3):994. https://doi.org/10.1039/c2ee23741e

van den Bosch S, Schutyser W, Koelewijn S-F, Renders T, Courtin CM, Sels BF (2015) Tuning the lignin oil OH-content with $\mathrm{Ru}$ and Pd catalysts during lignin hydrogenolysis on birch wood. Chem Commun (cambridge, England) 51(67):13158-13161. https://doi. org/10.1039/c5cc04025f
Vankoningsveld H, Jansen J, Vanbekkum H (1990) The monoclinic framework structure of zeolite H-ZSM-5. Comparison with the orthorhombic framework of as-synthesized ZSM-5. Zeolites 10(4):235-242. https://doi.org/10.1016/0144-2449(94)90134-1

Wang X, Rinaldi R (2012) Solvent effects on the hydrogenolysis of diphenyl ether with Raney nickel and their implications for the conversion of lignin. Chemsuschem 5(8):1455-1466. https://doi. org/10.1002/cssc.201200040

Wang H, Tucker M, Ji Y (2013) Recent development in chemical depolymerization of lignin: a review. J Appl Chem 2013:1-9. https:// doi.org/10.1155/2013/838645

Windeisen E, Wegener G (2008) Behaviour of lignin during thermal treatments of wood. Indus Crops Prod 27(2):157-162. https://doi. org/10.1016/j.indcrop.2007.07.015

Yang H, Yan R, Chen H, Lee DH, Zheng C (2007) Characteristics of hemicellulose, cellulose and lignin pyrolysis. Fuel $86(12$ 13):1781-1788. https://doi.org/10.1016/j.fuel.2006.12.013

Zhao C, Kou Y, Lemonidou AA, Li X, Lercher JA (2010) Hydrodeoxygenation of bio-derived phenols to hydrocarbons using RANEY® $\mathrm{Ni}$ and Nafion/SiO2 catalysts. Chem Commun. https://doi.org/10. 1039/B916822B

Publisher's Note Springer Nature remains neutral with regard to jurisdictional claims in published maps and institutional affiliations. 